\title{
The solution structure of Dead End bound to AU-rich RNA reveals an unprecedented mode of tandem RRM-RNA recognition required for mRNA regulation
}

\author{
Authors \\ Malgorzata M. Duszczyk ${ }^{1 *}$, Harry Wischnewski ${ }^{2}$, Tamara Kazeeva1, Fionna E. Loughlin ${ }^{1,4}$, Christine von \\ Schroetter ${ }^{1}$, Ugo Pradère ${ }^{3}$, Jonathan Hall ${ }^{3}$, Constance Ciaudo ${ }^{2}$, Frédéric H.-T. Allain ${ }^{1,5^{*}}$
}

\begin{abstract}
Affiliations
${ }^{1}$ Institute of Molecular Biology and Biophysics and ${ }^{2}$ Institute of Molecular Health Sciences, Department of Biology, ${ }^{3}$ Institute of Pharmaceutical Sciences, Department of Chemistry and Applied Biosciences, ETH Zürich, 8093, Zürich, Switzerland ${ }^{4}$ Present Address: Monash Biomedicine Discovery Institute, Department of Biochemistry and Molecular Biology, Monash University, Clayton, 3800 VIC, Australia ${ }^{5}$ Lead Contact
\end{abstract}

\section{Contact Information}

*To whom correspondence should be addressed.

E-mail: malgosia@mol.biol.ethz.ch (M.M.D.), cciaudo@ethz.ch (C.C.), allain@mol.biol.ethz.ch (F.H.T.A.)

\section{Author comment}

A previous version of this manuscript contained an error in the normalization of the luciferase activity in the cell-based assays in Figures 5 and S8. This has been corrected and the text has been updated accordingly.

\begin{abstract}
Dead End (DND1) is an RNA-binding protein essential for germline development through its role in posttranscriptional gene regulation. The molecular mechanisms behind selection and regulation of its targets are unknown. Here, we present the solution structure of DND1's tandem RNA Recognition Motifs (RRMs) bound to AU-rich RNA. The structure reveals how an NYAYUNN element is specifically recognized, reconciling seemingly contradictory sequence motifs discovered in recent genome-wide studies. RRM1 acts as a main binding platform, including unusual extensions to the canonical RRM fold. RRM2 acts cooperatively with RRM1, capping the RNA using an unusual binding pocket, leading to an unprecedented mode of tandem RRM-RNA recognition. We show that the consensus motif is sufficient to mediate upregulation of a reporter gene in human cells and that this process depends not only on
\end{abstract}


RNA binding by the RRMs, but also on DND1's double-stranded RNA binding domain (dsRBD), that we show to be dispensable for target binding in cellulo. Our results point to a model where DND1 target selection is mediated by an uncanonical mode of AU-rich RNA recognition by the tandem RRMs and a role for the dsRBD in the recruitment of effector complexes responsible for target regulation.

\section{Introduction}

Post-transcriptional gene regulation (PTGR) is orchestrated by an interplay between mRNA sequence and structure and its dynamic interactions with RNA binding proteins (RBPs). RBPs instantly cover mRNA transcripts as they are transcribed and are essential for all aspects of RNA metabolism like maturation, transport, cellular localization and turnover. Differential gene expression patterns depend on tissue-specific RBP levels and their combined interactions with the transcriptome. Misregulation of this process due to mutations in the RBPs or RNA they bind to is at the origin of a plethora of genetic diseases (Corbett 2018). Understanding how RBPs specifically recognize their mRNA targets and how this is connected to their downstream fate is therefore crucial to understand the complex PTGR networks involved in health and disease.

The germline is composed of highly specialized cells which must preserve a totipotent genome through generations. It succeeds in this through a highly specialized RNA metabolism regulating a highly complex transcriptome (Ramsköld et al. 2009; Seydoux and Braun 2006). Whereas $8 \%$ of all human proteins show highly tissue-specific expression, this is the case for only $2 \%$ of RBPs and the majority of these are found in the germline, reflecting its unique specialization (Dezso et al. 2008; Gerstberger et al. 2014a).

Dead End (DND1) is one of these few germline-specific RBPs. Conserved in vertebrates, it is essential for the specification and migration of primordial germ cells (PGCs), pluripotent germline precursors, to the future reproductive organs. These processes occur early in embryogenesis by blocking the expression of somatic genes, controlled by extensive post-transcriptional regulation (Licatalosi 2016; Seydoux and Braun 2006). DND1 deletion causes loss of PGCs by reactivation of somatic gene expression patterns in zebrafish (Gross-Thebing et al. 2017; Weidinger et al. 2003). In mice, truncations of DND1 (the so-called 'Ter-mutation') lead to male sterility and the formation of testicular teratomas (Ruthig et al. 2019; Youngren et al. 2005). 
Two mechanisms through which DND1 regulates mRNA transcripts have been proposed. First it was shown that DND1 stabilizes specific tumor suppressor mRNAs in a human tumor cell line (p27/CDKN1B and LATS2), as well as Nanos/TDRD7, essential factors for germline development, in zebrafish embryos, by preventing miRNA-mediated repression of these targets through the binding to conserved U-rich regions close to miRNA seed sequences in their mRNA 3' untranslated regions (3'UTRs). This would potentially block their accessibility to the RNA-induced silencing complex (miRISC) which would rescue translation (Kedde et al. 2007). Second, DND1 was shown to have an opposite effect and a wider role in germ cell PTGR by destabilizing a set of transcripts that must be cleared from developing germ cells to ensure survival, through non-miRISC mediated recruitment of the CCR4-NOT deadenylase complex (Suzuki et al. 2010; Yamaji et al. 2017).

Photoactivatable-ribonucleoside-enhanced crosslinking and immunoprecipitation (PAR-CLIP) assays revealed that targets crosslinked to DND1 are enriched in a UUU/UUA triplet and are associated with apoptosis, inflammation and signaling pathways (Yamaji et al. 2017). An additional digestion optimizedRIP-seq (DO-RIP-seq) approach described [A/G/U]AU[C/G/U]A[A/U] as RNA sequence motif enriched in DND1 targets (Ruthig et al. 2019). Transcriptome sequencing of the Ter mouse line, possessing a truncation in the DND1 gene, just before the formation of teratomas, showed two groups of DND1 targets either down- or up-regulated, involved in pluripotency and in differentiation respectively, in a sequential fashion, suggesting a dual and biphasic role for DND1. Overall, these functional and genome-wide motif identification studies using high-throughput methods are partly contradictory and the molecular details on how DND1 achieves target specificity remain elusive.

Most RNA binding proteins exert their specific functions by combining several copies of RNA binding domains to increase specificity and affinity to their targets (Afroz et al. 2015; Singh and Valcárcel 2005). DND1 has a unique domain structure, carrying two RNA recognition motifs (RRMs) connected by a remarkably short, four-residue inter-domain linker, which are followed by a double-stranded RNA binding domain (dsRBD) (Fig. 1A). This combination of domains is rare among RBPs and is only shared by DND1 and two other members of the hnRNPR-like subfamily (Marchler-Bauer et al. 2017) (Figs. S1A, S2). RRMs are the most abundant RNA binding domains in higher vertebrates, binding primarily single stranded RNA (Cléry et al. 2008; Gerstberger et al. 2014b). Their conserved canonical fold is $\beta \alpha \beta \beta \alpha \beta-a$ four-stranded anti-parallel $\beta$-sheet packed on top of two alpha-helices. Their canonical mode of RNA 
binding involves stacking of two consecutive RNA bases by exposed aromatic residues from the two conserved consensus sequences (RNP1 \& RNP2) in the first and third $\beta$-strands (Fig. S1B). The RRM has developed several strategies to increase specificity and affinity towards its targets by using extensions to the canonical fold with structural elements outside the $\beta$-sheet for RNA recognition and by employing several copies of the domain. While RRM1 appears to be a canonical RRM, RRM2 on the contrary does not have any aromatic residues in RNP1 and RNP2 (Figs. 1A, S1B, S2). Although several structures of tandem RRM-RNA complexes have been determined (Afroz et al. 2014; Deo et al. 1999; Kanaar et al. 1995; Lukavsky et al. 2013; Teplova et al. 2010; Wang and Tanaka Hall 2001), the great majority of them contains combinations of two canonical RRMs. It is therefore intriguing to understand if and how the tandem RRMs of DND1 can eventually cooperate to specifically recognize their RNA targets and if the dsRBD further influences RNA binding.

To address the question of how DND1 recognizes and represses its cellular targets at the molecular level, we first set out to understand the contribution of the three RNA binding domains of DND1 to target recognition. This revealed a crucial role for the RRMs while removal of the dsRBD had no effect on target binding. We then determined the solution structure of the DND1 tandem RRMs in complex with an AU-rich RNA. Our structure reveals binding to seven nucleotides with limited sequence-specific interactions generating recognition of a very degenerate NYAYUNN motif. Both RRMs participate in this RNA recognition via an unprecedented mode of cooperative binding. A canonical mode of binding by RRM1 is extended by additional secondary structure elements and contacts to RRM2 originating from $\alpha$-helix 2 which is unique amongst known RRM-RNA interactions. Our structure explains the degeneracies in the motifs enriched in DND1 targets in recent genome-wide studies. Finally, we show, using luciferase-based assays, that DND1 increases translation of a reporter gene independent of a miRNA-mimic repressing that target. We show that a single AU-rich element is necessary and sufficient for this effect, and that mutations in the RNA binding surface of DND1's tandem RRMs undo it. Surprisingly, a dsRBD truncation mutant also fails to increase target translation, suggesting that the dsRBD is an essential effector domain likely to recruit mRNA regulating factors. These results provide the first mechanistic and structural insights into the molecular mechanisms by which DND1regulates a subset of mRNAs and in turn stabilizes the fate of germ cells. 


\section{Results}

\section{DND1 binds CLIP/RIP targets in cellulo mainly through its RRM1}

There is some ambiguity in the published RNA motifs targeted by DND1. It was first reported, using reporter assays, that DND1 binds to U-rich regions of approximately 12 nucleotides in length in the vicinity of miRNA seed sequences in the 3'UTR of the CDKN1B/p27 tumor suppressor mRNA, with the sequences UUUUUCCUUAUUU and UUUUUACCUUUU (Kedde et al. 2007). Much later, genome-wide PAR-CLIP studies defined a much shorter UUU/UUA triplet motif (Yamaji et al. 2017) and very recently a Digestion Optimized-RIP approach revealed [A/G/U]AU[C/G/U]A[A/U] as motif enriched in DND1 targets (Ruthig et al. 2019). A single RRM usually binds 4-6 nucleotides (Cléry et al. 2008). To understand how DND1's two RRMs cooperate with the dsRBD to recognize an RNA target, we set out to define the contributions of each domain to RNA binding. We first selected published DND1 targets and validated them using RNA immunoprecipitation from HEK293T transiently expressing either wildtype (WT) or mutant FLAG-tagged DND1. Mutant 1-235 lacks the dsRBD but includes the extended RRM2, making it longer than the Ter-mutation truncation (Youngren et al. 2005), which is located in the middle of RRM2 $\alpha$-helix 2 (Fig. 1A). R98A is a mutant of the conserved RNP1 sequence in RRM1 (Figs. 1A, S1B). The RIP was followed by quantitative PCR using primers for two DND1 targets revealed by PAR-CLIP and DO-RIP (Fig. 1B). Phorbol-12-Myristate-13-Acetate-Induced Protein 1 (PMAIP1), a cell cycle regulator promoting apoptosis, is the target with the highest normalized 3'UTR read counts in the PAR-CLIP dataset (Yamaji et al. 2017). Survival of Motor Neuron (SMN) protein is a small nuclear ribonucleoprotein (snRNP) assembly factor. Its pre-mRNA SMN1 is expressed at an order of magnitude lower level than PMAIP1 in HEK293 and is enriched in the DO-RIP dataset (Ruthig et al. 2019). As a negative control, we used solute carrier family 25 member 6 (SLC25A6), with HEK293 mRNA levels in the same order of magnitude as PMAIP1. In our RIP assays using both the full-length WT DND1 and a truncation mutant lacking the dsRBD, the enrichment over the input is increased for the two targets compared to the control (Figs. 1B, S3B). Pulldown by the full-length R98A mutant results in a level of target enrichment comparable to the negative control pulled down by the WT DND1. These data suggest that RRM1 might be utilized as an essential RNA binding interface in cells, while the dsRBD appears to be dispensable for RNA binding, at least for these two abundant targets. The role of RRM2 could not be tested considering the non-canonical nature of this RRM as its RNA interaction surface could not be 
predicted. Therefore, we next decided to investigate the contribution of the individual RRMs to RNA binding in vitro.

\section{DND1's tandem RRMs cooperatively bind AU-rich RNA with high affinity}

To define high affinity RNA targets for the individual RRMs, we recombinantly expressed and purified the separate RRM domains, including the conserved $\mathrm{N}$ - and C-terminal extensions (Figs. 1A, S2). We then tested their binding to short oligonucleotides derived from the p27 URRs (Kedde et al. 2007) using Isothermal titration calorimetry (ITC) to monitor thermodynamic changes upon ligand binding (Fig. 2ACDE). In addition, we used NMR titrations, series of two-dimensional ${ }^{1} \mathrm{H}-{ }^{15} \mathrm{~N}$ HSQC spectra of protein with increasing RNA concentrations, to observe backbone amide proton chemical shift perturbations caused by RNA binding (Fig. 2B and S4ABC). We found that RRM2 alone does not bind any of the oligos (Fig. S4A) and that only an oligo including a central adenosine (UUAUUU) has enough affinity to RRM1 to show significant chemical shift perturbations in an NMR titration (Fig. S4B). The affinity of a slightly longer oligo CUUAUUUG to RRM1 is larger than $54 \mu \mathrm{M}$ as measured by ITC (Fig. 2C). Surprisingly, the affinity to this sequence increased over 80 -fold $\left(0.68 \mu \mathrm{M} \mathrm{K} \mathrm{K}_{\mathrm{D}}\right)$ when titrated to the tandem RRM domains showing a role for RRM2 in RNA binding (Fig. 2A). NMR titration of UUAUUU to DND1 RRM12 indicates a change from fast to intermediate exchange on the chemical shift timescale and saturation of most residues at a 1:1 ratio, which is consistent with the increased affinity measured by ITC (Fig. 2B). Large chemical shift changes throughout the ${ }^{1} \mathrm{H}-{ }^{15} \mathrm{~N} \mathrm{HSQC}$ spectrum indicate major structural rearrangements of the tandem RRMs upon RNA binding. Additional ITC and (Fig. 2CDE) NMR titrations (Fig. S4C) showed that only the tandem RRMs, not the single domains, have some affinity to U-rich oligos not containing adenosines or with an adenosine at the periphery such as UUUUUAC $\left(>35 \mu \mathrm{M} K_{D}\right)$ and UUUUUCC $\left(>100 \mu \mathrm{M} K_{D}\right)$. The in vitro binding measurements are summarised in Table S2. Taken together the results above indicate that the DND1 tandem RRMs cooperatively bind AU-rich RNA targets of approximately 7-8 nucleotides in length, with the highest affinity when the adenine is in a central position. 


\section{The solution structure of DND1's tandem RRMs bound to CUUAUUUG RNA}

To understand the mechanism of cooperative binding of DND1's tandem RRMs and their preference to AU-rich over U-rich RNAs, we solved the structure of the extended RRM12 in complex with the CUUAUUUG RNA target using NMR spectroscopy (Table 1, Fig. 3). The assignment procedure of protein and RNA and the structure calculation protocol is outlined in the Methods details. DND1 RRM12 showed poor solubility and in the final stages of purification was purified in complex with the target RNA. Use of selectively ribose ${ }^{13} \mathrm{C}$-labeled CUUAUUUG RNA prepared by solid phase synthesis from phosphoramidites helped resolving spectral overlap of critical residues, greatly aiding assignments of resonances and intermolecular NOEs (Fig. S5A). We could calculate a precise structural ensemble of this $27.5 \mathrm{kDa}$ protein-RNA complex using unambiguous intra-protein (4947), intra-RNA (150) and intermolecular (103, Table S3) NOE-derived distance restraints. The isolated domains within this ensemble of 20 conformers converge to a root mean square deviation (RMSD) of $0.95 \AA$ (RRM1), $0.57 \AA$ (RRM2) and the $\mathrm{U}_{3} \mathrm{~A}_{4} \mathrm{U}_{5} \mathrm{U}_{6} \mathrm{U}_{7}$ RNA nucleotides to an RMSD of $0.6 \AA$ for all heavy atoms (Figs. $3 A B$, Table 1). The global complex was initially less well defined due to a lack of direct contacts between RRM1 and RRM2 and a limited number of restraints that could orient the domains through the RNA. We did expect a well-defined orientation between RRM1 and RRM2 in the complex though, as ${ }^{15} \mathrm{~N} \mathrm{T1}$ and T2 relaxation measurements indicated the protein-RNA complex behaves as a rigid globular protein of approximately $30 \mathrm{kDa}$ in solution as opposed to two domains tumbling independently (Fig. S5B). We included 127 Residual Dipolar Couplings (RDCs) from amide bonds to increase precision and obtained a precise final ensemble of 20 conformers with an RMSD of $1.26 \AA$ for all heavy atoms (Fig. 3C, Table 1).

Our structure reveals a number of unusual structural features including unprecedented modes of RRM:RNA recognition. The fold of RRM1 is non-canonical with the conserved N-terminal extension folding into a $\beta$-hairpin packed on top of an $\mathrm{N}$-terminal $\alpha$-helix. This structural element is tightly packed against the side of the RRM1 to create an extended surface (Fig. 3A), in an identical fashion as the extension of RRM1 in the RNA-binding protein hnRNPQ/SYNCRIP (Hobor et al. 2018). This extended RRM (eRRM) fold is conserved in all members of the hnRNPR-like family of RNA binding proteins (Figs. S1, S6). RRM2 is followed by the conserved C-terminal helical extension lacking contacts to the core canonical RRM2 fold (Fig. 3B), as confirmed by the relaxation data which shows this helix tumbling 
independently in the tandem RRM-RNA complex (Fig. S5B). The RNA is bound in a canonical 5' to 3' fashion over $\beta 4$ through to $\beta 2$ using the RNP residues of RRM1 but is sandwiched between the two domains (Fig. 3D), burying the central UAUUU nucleotides in a positively charged channel (Fig. 3E). In addition to the primary RNA binding surface on RRM1, the conserved N-terminal hairpin extension is used to extend RNA binding for a longer sequence compared to canonical RRMs. Finally, and most surprisingly, this RNA binding is stabilized by RRM2 using an unprecedented binding pocket formed by RRM2 $\alpha$-helix 2 and the edge of its $\beta 4$, while the non-canonical $\beta$-sheet of RRM2, missing conserved aromatic RNP residues, is turned away from the RNA. Additional protein-RNA contacts are facilitated by the backbone and sidechains of the four-residue interdomain linker. This structure explains well the increase in RNA binding affinity of the tandem RRMs compared to RRM1 in isolation.

\section{Structural details: specific readout by DND1's tandem RRMs}

DND1's tandem RRMs directly bind primarily the central 5 nucleotides (bold) of CUUAUUUG RNA

(Fig. 4). The intermolecular contacts are represented in a schematic fashion in Figure $4 A . U_{3}$ and $A_{4}$ are bound in a canonical fashion over the RRM1 $\beta$-sheet surface, their bases interacting with $\beta 4$ and $\beta 1$ respectively. The $\mathrm{U}_{3} \mathrm{O} 2$ is hydrogen-bonded to the $\mathrm{C} 132$ sidechain and its sugar ring contacts L130. This contact is not fully specific as likely a C would also be accepted in this position keeping this $\mathrm{H}$-bond intact. The $\mathrm{A}_{4}$ base is stacked on F61 in RNP2 and its sugar ring interacts with F100 from RNP1 in a canonical manner (Fig. 4B). This is illustrated by unusual chemical shifts of the $A_{4}$ ribose carbons and protons (Fig. S5A). The $A_{4}$ base is sequence-specifically recognized via hydrogen-bonds to its Hoogsteen edge (N4 amino and N7) from side-chains and main-chains of the highly conserved interdomain linker (R133, S134 and T135) (Figs. 4B, C). We see variability in the $\mathrm{H}$-bond partners to $A_{4}$ in the structural ensemble, which reflects the exchange-broadening we observe for the backbone resonances of these linker residues.

From $\mathrm{U}_{5}$ onwards the protein-RNA interactions deviate from canonical binding. While in a canonical RRM the $U_{5}$ base would be expected to stack on the RNP2 Y102, here $U_{5}$ rather stacks on top of the $A_{4}$, as evidenced by strong NOEs between $A_{4} \mathrm{H}_{1}$ ' to the $\mathrm{U}_{5} \mathrm{H} 5$ and $\mathrm{H} 6$ resonances and weaker NOEs between $A_{4} \mathrm{H} 8$ to the $U_{5} \mathrm{H} 6$ resonance (Table S3). The sugar ring of $U_{5}$ is packed against $\mathrm{Y} 102$, F100 and M90 (Fig. 4C) and its base functional groups are involved in hydrogen-bonding with the conserved interdomain linker backbone and sidechains (e.g. the S134 hydroxyl, T135 backbone 
amide and K137 NH3, Figs. 4B, D) and with the Y102 hydroxyl. Although part of this H-bonding network would be lost, e.g. the contact to K137, a C could be accepted in this position too using an alternative $\mathrm{H}$-bonding partner, so this contact is likely not fully sequence specific.

The most surprising element of the structure is the involvement of a highly conserved binding pocket of RRM2 in the specific recognition of $U_{6}$. $U_{6}$ lies under RRM2 $\alpha$-helix 2 with its ribose ring in contact with A193, M194 and K197 and its base carbonyl O4 hydrogen-bonded by both the NH3 of K196 and the sidechain HE1 of W215 (Fig. 4D). This double H-bond to O4 makes this contact fully sequence specific. Contacts to the $U_{6}$ and $U_{7}$ phosphate groups by $\mathrm{H} 189$ and $\mathrm{K} 197$ sidechains, respectively, further stabilize the $U_{6}$-RRM2 interaction, defined by a large number of intermolecular NOEs (Fig. S5A). These interactions with RRM2 $\alpha$-helix 2, grabbing the $U_{6}$ nucleotide like a claw, allow for an unusual reversal of the RNA backbone direction at $U_{6}$ which is rotated by 120 degrees (around a vertical axis in Fig. 4D) compared to $U_{5}$. The contacts to the $U_{6}$ phosphate group by $R 88$ and $Q 39$ of RRM1 (Fig. 4E) help positioning the two RRMs relative to each other and explain their cooperative binding since both RRMs contribute to $U_{6}$ binding.

The $U_{7}$ phosphate is fixed by a salt bridge to $\mathrm{K} 197$ on RRM2 while the sidechain NH2 of N37 on the tip of the N-terminal eRRM1 hairpin extension interacts with the $\mathrm{G}_{8}$ phosphate (Fig. 4D). The $\mathrm{U}_{7}$ base is not sequence-specifically recognized. Finally, the $\mathrm{G}_{8}$ nucleotide is not well defined. Overall, in this conformation all phosphate groups from $U_{3}$ to $G_{8}$ are hydrogen-bonded to one or two protein sidechains with some originating from the RRM1 extension (N37 on $\beta$-strand -1 and Q39 on $\beta$-strand 0). Altogether this structure suggests the recognition of a $\mathrm{N}_{2} \mathrm{Y}_{3} \mathrm{~A}_{4} \mathrm{Y}_{5} \mathrm{U}_{6} \mathrm{~N}_{7} \mathrm{~N}_{8}$ consensus sequence (where $\mathrm{Y}$ is a pyrimidine) by DND1s tandem RRMs as in the positions of $U_{3}$ and $U_{5}$ cytosines could be accepted while keeping the $\mathrm{H}$-bond network at least partly intact.

The binding topology on the eRRM1 and RRM2 is unprecedented with for the first time the involvement of a nucleotide binding pocket in $\alpha$-helix 2 of an RRM. As the $\beta$-hairpin extension and RNA binding residues on eRRM1 are conserved in the hnRNPR-like family of RNA binding proteins (Figs. S1, S6) it is likely that the RNA binding mode of the eRRM1 is conserved. Although the interdomain linker, comprised of amino acid residues TEK, is unique for DND1 within this family, it is possible that the linkers of the other family members could bind RNA in a similar fashion but using 
an alternative $\mathrm{H}$-bonding network. Notably, DND1 is the only family member with a non-canonical $\beta$ sheet binding surface for RRM2, lacking aromatic residues.

\section{Mutation of key RNA binding residues compromises the RNA interaction in vitro.}

To further understand the structure, we replaced several RNA interacting residues of DND1's tandem RRMs with alanine and tested the effect of these substitutions on RNA binding by NMR titrations, after making sure that the protein fold was not affected (Fig. S7A). The mutant of a canonical RRM1 RNP residue R98A failed to bind CUUAUUUG (Fig. S7B), confirming in vitro that the eRRM1 is the primary RNA binding surface of DND1 as shown by our RNA-IP and qPCR experiments (Figs. 1B, S3). Of note, other RRM1 RNP mutants could not be tested. Although we could express mutant F61A, it precipitated during the purification, while Y102A could not be expressed in the soluble fraction at all, despite the fact that its equivalents were used in several studies as RNA binding mutants (Goudarzi et al. 2012; Kedde et al. 2007; Mei et al. 2013; Slanchev et al. 2009). Although its solubility in cellulo and in vivo might be improved, its inactivity could result from an overall instability of the protein. Mutation of M90 on $\beta 2$ of eRRM1, a residue interacting with $U_{5}$, also abolishes RNA binding (Fig. S7B). Although the linker T135 sidechain makes several specific contacts with $\mathrm{A}_{4}$ or $\mathrm{U}_{5}$, mutation of this residue to $\mathrm{A}$ does not reduce RNA binding. Most likely other residues in the linker could compensate using an alternative $\mathrm{H}$-bonding network for binding to $\mathrm{U}_{5}$. K197A and W215F mutations of residues of the unusual RNA binding pocket of RRM2, result in weaker binding. Smaller chemical shift changes are seen in W215F compared to the WT upon RNA titration. In the K197A mutant, the NMR signals of the complete RRM2 $\alpha$-helix 2 are exchangebroadened in the RNA-bound state, indicating a less stable RNA binding. We performed ITC experiments (Fig. S7C) to quantify the loss of RNA binding and obtained Kd values of $2.6 \mathrm{uM}$ for K197A and > 10uM for W215F compared to 0.7 M for the WT DND1 RRM12 binding to CUUAUUUG (Fig. 2A). These are not nearly as high as the Kd for RRM1 alone (>54 uM, Fig. 2C) suggesting that these single mutations do not fully destroy the RRM2 binding pocket. These assays confirm that the eRRM1 RNP is essential for RNA binding and that the novel RRM2 binding pocket stabilizes the primary eRRM1-RNA interaction. 


\section{Introduction of an AU-rich motif into a reporter gene 3'UTR is necessary and sufficient for target repression by DND1}

To investigate how the reduced RNA binding caused by these mutations affects DND1's function in cellulo, we set out to test these single amino-acid mutants in the context of the full-length protein, in a luciferase-based gene reporter assay. Kedde et al. used such assay earlier to show that DND1 protects certain mRNA targets from miRNA-mediated repression (Kedde et al. 2007). As reporter, we transfected the psiCHECK2 dual luciferase plasmid with a partial p27/CDKN1B 3'UTR sequence into HEK293T cells. The partial UTR, cloned downstream from the Renilla luciferase ORF, contains two miR-221 seed sequences and two putative DND1 binding sites, identical to the sequence shown by Kedde et al. (Kedde et al. 2007) to be sufficient for protection of the target by DND1. Upon co-transfection of a miR221-3p mimic (miRIDIAN, Dharmacon), as expected we observed a decrease of the luciferase activity compared to the co-transfection of a negative control scrambled miRNA mimic (Fig. S8). Introduction of a plasmid expressing FLAG-tagged wild-type DND1 increased p27-3'UTR-controlled luciferase translation but this was independent of which miR-mimic was transfected - either the miR221-mimic targeting the UTR or the negative control, and this effect was only strong and significant in the presence of the negative control miR mimic. We conclude that DND1 has a stabilizing effect on the p27/CDKN1B 3'UTR target which is independent of miRNA targeting. The effect of the R98A and 1-235 dsRBD truncation mutants does not differ significantly from the WT. We reasoned that possibly DND1 is not able to displace the miR-221 mimic that is present in abundance in the cell and tightly bound to the targets before the protein has reached an optimal expression level. We therefore used the strong enhancing effect observed in this assay to test the role of RNA binding in DND1 function. We inserted the full 3'UTR from the telomerase reversed transcriptase gene (TERT) into the psiCHECK2 dual luciferase plasmid. It is not expected to be targeted by DND1 as it lacks AU-rich regions and was not found among the recent CLIP and RNA-IP DND1 target datasets (Ruthig et al. 2019; Yamaji et al. 2017). Upon transfection of this reporter into HEK293T cells together with expression plasmids for either wildtype or mutant full-length FLAG-tagged DND1, we indeed do not observe any effect on luciferase activity (Fig. 5). Yet, insertion of a single UAUUU (the central pentanucleotide bound to the tandem RRMs in our structure) into the TERT 3'UTR is sufficient to increase luciferase activity upon transfection of wildtype DND1. This increase is even more significant when two consecutive UAUUU sequences (spaced by a UUUU tetranucleotide) are introduced. Transfection of the R98A eRRM1 RNP mutant or the 
truncation mutant lacking the dsRBD (DND1 1-235) does not increase the luciferase activity. These results indicate that the presence of an AU-rich motif in the 3'UTR is necessary and sufficient for DND1mediated target regulation. The fact that the dsRBD-truncation mutant cannot enhance luciferase activity although this mutant can bind RNA (Figs. 1B, S3), suggests that the dsRBD is likely to have a downstream role in DND1-mediated gene.

\section{Discussion}

\section{Unique arrangement of DND1's tandem RRMs dictates conformation, orientation and accessibility of bound RNA}

We determined the solution structure of DND1's extended tandem RRMs in complex with AU-rich RNA and show the molecular details of target RNA recognition by this RNA binding protein that is essential for germ cell survival in higher vertebrates. Previously solved tandem RRM-RNA complexes have shown either formation of a cleft, like Sex-Lethal (SxI)(Handa et al. 1999) and Human Antigen D (HuD - Fig. 6A)(Wang and Tanaka Hall 2001), or extended surfaces (Poly-A Binding Protein (PABP - Fig. 6B)(Deo et al. 1999) and TAR DNA-binding protein 43 (TDP-43 - Fig. 6C)(Lukavsky et al. 2013) by the two canonical $\beta$-sheet surfaces accommodating the RNA. In all these structures RNA stretches between 8-10 nucleotides are bound in a canonical fashion, with higher affinity and specificity than if a single domain is used. In all the tandem RRMs mentioned above, the bound RNA adopts an extended conformation. The RRM-RRM orientation and RNA binding topology are completely different in our DND1-RNA structure, which is a result of four structural features found so far only in this complex: lack of a canonical RNA binding surface for RRM2, an ultra-short inter-RRM linker, an extended RNA binding surface of eRRM1 and finally, the presence of an unprecedented RNA binding pocket on $\alpha$-helix 2 of RRM2. The complex embeds only a short canonical RNA binding stretch $\left(U_{3}-A_{4}\right)$, which is followed by binding of $U_{5}-U_{7}$ in a very unusual manner. Indeed, $U_{6}$ is bound by RRM2 $\alpha$-helix2, resulting in a 120-degree rotation of $U_{6}$ compared to $A_{4}$ and the $U_{6}$ phosphate, $U_{7}$ ribose and $G 8$ phoisphate are bound by the tip of the eRRM1 extension. Binding by the linker residues supports the RNA in this unique conformation, its short length being likely crucial to bridge nucleotides specifically recognized by RRM2 and eRRM1. The path 
of the RNA backbone is reversed, and the RNA is more compacted than in previously determined tandem RRM-RNA complexes, the $U_{3}-G_{8}$ phosphates spanning approximately $21-23 \AA$ (Fig. $6 D$ ), while e.g. in PABP an equivalent stretch of 6 nucleotides spans approximately $26-28 \AA$ (Fig. 6B). Such backbone reversal capacity might help to fold the RNA, or the tandem RRMs might be suited to recognize an RNA that is in an extended stem-loop conformation. Also, the central RNA residues are not solvent accessible compared to other tandem RRM-RNA complexes. This structural feature would be consistent with the possibility that DND1 acts as a steric inhibitor of effector complexes targeting proximal binding sites like suggested for the miRNA seed sequences targeted by miRISC in p27/CDKN1B and LATS2 (Kedde et al. 2007).

\section{Structural extension of the eRRM1 increases RNA binding affinity and stabilizes a backbone turn in the recognized RNA.}

While several extensions to the canonical RRM fold have been described, either extending the $\beta$-sheet surface by one or several strands or adding an $\alpha$-helix at the N-or C-terminus (Afroz et al. 2015), the DND1 $\mathrm{N}$-terminal extension of a $\beta$-hairpin packed on a third $\alpha$-helix is so far restricted to the hnRNPRlike family of proteins (Figs. S1, S6). An X-ray structure of such eRRM from another member of this family, SYNCRIP/hnRNPQ in its free form has been published recently (Hobor et al. 2018) and is highly similar to the DND1 eRRM1 with the exception of the formation of the $\beta 3^{\prime} / 3^{\prime \prime}$ hairpin and a small shift in the orientation of the $\mathrm{N}$-terminal extension. These differences are likely due to RNA binding in our structure or the presence of an additional N-terminal acidic domain (AcD) found in the SYNCRIP structure. Our structure reveals that this $\beta$-hairpin packed on a third $\alpha$-helix is essential for increasing the affinity to the RNA by fixing the backbone of $U_{6}$ and $G_{8}$ on the eRRM1 via Q39 and N37 (Figs. 4D, E). Therefore, it is crucial for stabilizing the turn in the backbone observed in our complex. This is reminiscent of other extensions found in the RRM contributing to RNA binding like the $\beta$-hairpin found in FUS RRM (Loughlin et al. 2019) (Fig. 6E) and the fifth $\beta$-strand of PTB RRM2 (Oberstrass et al. 2005) (Fig. 6F).

\section{The hrRRM2 presents a novel RNA binding pocket and its integrity is necessary for DND1 function.}

We have shown that the primary RNA interaction interface of DND1 lies on eRRM1. It is the proximity of the second RRM, lacking a canonical RNA binding interface, but presenting a novel pocket for 
stabilization of this primary binding, that makes the RNA binding topology by DND1's tandem RRMs unprecedented. Structures of several types of RRM domains without aromatic residues on the $\beta$-sheet surface have been described (Afroz et al. 2015). The qRRMs of hnRNPF use their $\beta 1 / \alpha 1, \beta 2 / \beta 3$, and a2/ß4 loops for recognition of G-rich sequences (Dominguez et al. 2010), while the URRM of SRSF1 uses a conserved motif in the $\alpha$-helix1 for purine-rich RNA binding (Clery et al. 2013). However, our structure is the first example of an RRM mediating RNA binding via $\alpha$-helix 2 . We propose to call an RRM using this interface for RNA binding the hrRRM for hnRNPR-like family related RRM. We demonstrated the importance of the binding pocket on RRM2 by mutational analysis using in vitro binding assays and ITC (Fig. S7BC). It is also supported by its almost full conservation, not only in DND1 (Fig. S2) but also other members of the hnRNPR-family (Fig. S6). Thus, its RNA binding mode is likely to be conserved. Our RRM2 structure is highly similar to the structure of the free RRM2 of RBM46 (RNA binding motif protein 46, PDB: 2DIS)(Dang et al. 2006) including the orientation of the residues of the novel binding pocket. The importance of this pocket for DND1 function was demonstrated in functional studies in zebrafish where the equivalent to the K197 mutant (K200T) was the only mutant outside of RRM1 causing loss of function (Slanchev et al. 2009). Nearly all other loss-of-function mutants in this study can be explained using our structure. We already discussed the zebrafish Y104 RNP mutant: the equivalent of $\mathrm{Y} 102$ in humans, is unstable in vitro. Even if it would be stable in vivo, interactions with $\mathrm{U}_{5}$ would be lost. The equivalents of Y72, F89 and H121 in zebrafish dnd1 are Y70, F87 and H119 in human DND1. They are important structural residues stabilizing the RRM fold. Y70 is particularly important for interaction between $\alpha$-helices 0 and 1 in eRRM1, linking the core RRM fold and the N-terminal eRRM extension. Mutation of these residues most likely disrupts the fold of eRRM1. The only loss-of-function mutant that is not that easily explained is $\mathrm{N} 94 \mathrm{~K}$, a mutant of the equivalent T92 in the human protein, situated in the $\beta 2-\beta 3$ loop. This residue is in close proximity to $G_{8}$ in our structure, but not well enough defined to interpret a specific interaction with the RNA. In the context of a longer RNA it could very well be involved in such specific binding. Finally, it should be mentioned that the Ter mutation, causing germ cell loss and testicular teratomas in mice (Youngren et al. 2005), is a truncation at the equivalent of R190 in $\alpha$-helix 2, demonstrating that RRM2 and the dsRBD are essential domains for DND1 function. The novel binding pocket in RRM2 increases affinity and specificity to the readout of eRRM1 and creates a remarkable turn in the RNA backbone. 


\section{Limited sequence specificity leads to plasticity of RNA recognition}

The RNA recognition observed in our structure unifies seemingly contradictory data present in the literature as to the RNA recognition elements found enriched in DND1 targets. In fact, a combination of a UUA/UUU triplet as enriched in CLIP (Yamaji et al. 2017) was used in our structure determination as the RNA target. The motif $Y_{3} A_{4} Y_{5} U_{6} N_{7} N_{8}$ derived from our structure also fits with the [A/G/U]AU[C/G/U]A[A/U] motif enriched in RIP targets (Ruthig et al. 2019). Moreover, this motif may be interpreted as a repetition of the UAU motif, containing 2 adenines that are specifically recognized in our structure. We have not tested binding to an oligonucleotide containing two spaced adenines, but the avidity effect of RBPs binding to repetitions of high affinity motifs, increasing affinity, has been demonstrated for several other RRM-containing proteins: hnRNPG (Moursy et al. 2014), PTB (Oberstrass et al. 2005), hnRNP C (Cieniková et al. 2014) and more recently HuR (Ripin et al. 2019). Our structure also provides some insight how the residues outside of the YAY motif could be recognized. For example, the binding pocket on RRM2 specifically recognizing $U_{6}$ in our structure (Fig. 4D) could not accommodate a $\mathrm{C}$ without losing the double $\mathrm{H}$-bond to the $\mathrm{O} 4$ Overall, it looks like DND1's tandem RRMs demonstrate a certain plasticity for RNA recognition where a range of sequences can be bound, but a $\mathrm{Y}_{3} \mathrm{~A}_{4} \mathrm{Y}_{5} \mathrm{U}_{6}$ is necessary for high affinity binding. Such high affinity binding could be a prerequisite for the activation of downstream processes like the recruitment of regulatory factors (Webster et al. 2019).Here, we propose that the tandem RRMs bind RNA in a two-step mechanism. In a first step a range of sequences may be preselected by low affinity binding in order to attach DND1 to scan the 3'UTR (Fig. 6G panel a). Upon encountering a high-affinity YAYU element DND1 pauses at the central adenine $\left(A_{4}\right)$, while RRM2 locks the uridine $\left(U_{6}\right)$ in its hrRRM binding pocket which can then initiate downstream processes from a fixed position (Fig. 6G panel b).

\section{Role of the dsRBD}

We have shown that DND1's tandem RRMs, like the majority of RRMs, are relatively sequence tolerant (Afroz et al. 2015). On the other hand, we know that linear sequence motifs are often insufficient to fully capture RBP binding specificities (Dominguez et al. 2018). Specificity may be increased due to contextual features, either in the form of bipartite motifs, such as recently found for FUS (Loughlin et al. 2019), preference for a nucleotide composition flanking a high affinity linear motif, or due to the favoring of specific structural motifs adjacent to the linear motif. The fact is that while the RNA binding surfaces 
of the tandem RRMs are highly conserved within the hnRNPR-like family of proteins, the sequences of the dsRBDs of DND1, RBM46 and ACF1 (APOBEC1 complementation factor) are not that well conserved (Fig. S6B). Thus, DND1's highly specialized function in germline development might originate from this domain. We have shown that DND1's dsRBD is required for target regulation, either through direct or indirect recruitment of effector proteins or maybe simply by displacing other factors, but also that DND1's dsRBD is not essential for the binding of several highly abundant RNA targets (Figs. 1B, S3). Although DND1's dsRBD lacks some canonical RNA recognition residues (Masliah et al. 2013) (Fig. S6B), we cannot exclude a non-canonical RNA binding surface to contribute to the binding to a different set of targets. The dsRBD could increase DND1's target specificity by recognizing a stem-loop motif adjacent to the linear motif recognized by the tandem RRMs. While we know that 3'UTRs are highly structured not only in vitro but also in vivo (Beaudoin et al. 2018), it is to be investigated if the 3'UTRs in the vicinity of the linear motifs targeted by DND1 are indeed enriched in secondary structure. Further structural studies should be undertaken to confirm that such structures can indeed be recognized by the full length DND1. Another possibility for increasing target specificity by DND1 is cooperation with a binding partner, as has been reported for NANOS2 (Suzuki et al. 2016), which has been shown to interact with CCR4-NOT (Suzuki et al. 2010, 2012), or other germline-specific RNA binding proteins.

\section{DND1 as a germline-specific AU-rich element binding protein}

DND1 binds UAUU which is contained in AU-rich sequence elements (AREs) in 3'UTRs that have been known for many years to target mRNAs for rapid degradation in mammals. AREs are divided into three classes with respect to the copy number of the canonical pentamer AUUUA sequence: several copies are dispersed between U-rich regions in class I, clustered in class II, while class III are predominantly U-rich but lacking these canonical pentamers (Peng et al. 1996). More than 20 AU-rich RNA binding proteins (AUBPs) have been identified, they control the fate of ARE-mRNAs (Wu and Brewer 2012). Because DND1 CLIP and RIP-enriched targets do not necessarily contain the canonical ARE AUUUA pentamer target sequence, DND1 can be classified as a germline-specific AU-rich RBP (AUBP) targeting class III AREs. Although the recruitment of degradation machineries to mRNAs for their destruction is a unifying mechanism between several AUBPs (Chen et al. 2001; Chou et al. 2006; Lykke-Andersen and Wagner 2005), it does not necessarily need to be shared by DND1. As multiple AUBPs may modulate the stability and translation of a single ARE-mRNA, questions 
of functional redundancy and additivity or antagonism arise. It is likely that variations in the relative amounts of mRNAs, the AUBPs present in a certain cell type or developmental stage and in the binding affinities, determine both the identity of the targeted mRNAs and their fate (Webster et al. 2019). Therefore, the sole fact that DND1 is specifically expressed in the germline will be a major contributing factor to its target specificity. This questions the relevance of recognition motif derivation in large-scale DND1-RNA interaction studies performed in non-native cell types with transcriptomes differing from developing germ cells and using cross-linking that might overrepresent low affinity motifs. The structural and biophysical work in this study contributes to the understanding of what the requirements are for a high affinity motif for DND1 and helps to reinterpret previous studies in order to understand the complex gene regulation networks during germline specification.

We have demonstrated that DND1 prefers AU-rich over U-rich RNAs and that a central adenine is required for high-affinity binding. The adenine is specifically recognized by the eRRM1 binding pocket involving RNP2 and the interdomain linker (position ' $\mathrm{N}_{1}{ }^{\text {). }}$. This contrasts with the RRM3 of another AUBP, HuR, that recognizes both AU-rich and U-rich sequences with similar affinities, the latter slightly higher due to an avidity effect (Ripin et al. 2019). Adenines are bound by HuR RRM3 in two different positions: either on the periphery, or $\beta$-strand 3 using RNP1 (position ' $\mathrm{N}_{2}$ '). Adenines are important to localize the protein at a precise position within the 3'UTR. Such a 'locking' mechanism is also present for the cytoplasmic polyadenylation element (CPE)-binding (CPEB) family of RNA-binding proteins. These RBPs bind the CPE sequence UUUUAU, which activates translation by cytoplasmic polyadenylation. The CPEB4 and CPEB1 tandem RRMs bind a UUUUA pentanucleotide sequencespecifically (Afroz et al. 2014). While the uridines are bound by RRM1, the adenine is specifically recognized by RRM2 using RNP2 (position ' ${ }_{1}{ }^{\prime}$ ). RRM1 in isolation has low affinity to U-rich RNAs and RRM2 does not bind U-rich sequences. Therefore, it is proposed that the protein is recruited to U-rich motifs through RRM1, after which it scans the 3'UTR in an open conformation until it encounters an adenine in a consensus CPE and locks the protein on this sequence. This is a similar mechanism as we propose here for DND1, although in our case the scanning for a high-affinity motif likely happens in a closed rather than open conformation as the isolated RRM1 does not bind U-rich sequences. This original mode of RNA target selection therefore appears to be a general mechanism for cytoplasmic RNA binding proteins regulating RNA via their 3' UTR. 
In conclusion, we provide here the first structural and mechanistic insight into the molecular mechanisms by which the RNA binding protein DND1 regulates a subset of mRNAs and in turn might stabilize the fate of germ cells. Our results hint at a specialized function of DND1's individual RNA binding domains where the tandem RRMs are mainly responsible for target binding and the dsRBD for target regulation, possibly through the recruitment of regulatory factors, other RBPs that modulate DND1's target specificity, or displacement of competing RBPs. Our structure unifies DND1 RNA recognition elements recently found enriched in genome-wide interaction studies and facilitates understanding of loss-offunction mutants previously described in the literature. In addition, we have demonstrated yet another way in which an RNA recognition motif can recognize RNA, extending the repertoire of this versatile and abundant RNA binding domain.

\section{Acknowledgments}

We are grateful to Gunter Stier (BZH, Universität Heidelberg) and Dr. Arie Geerlof (PEPF Helmholtz Zentrum München) for providing us with expression plasmids and protocols that were developed at EMBL Heidelberg. We thank Dr. Julien Boudet for assistance with ITC measurements, Dr. Antoine Clery for cloning the RRM2 expression plasmid and assistance with ITC, Dr. Fred Damberger for assistance with NMR experiments and structure calculations, Dr. Markus Blatter and Dr. Yaroslav Nikolaev with structure calculation and IT support respectively, Mauro Zimmermann for assistance with RNA preparation, Dr. Daniel Cirera-Salinas for cloning the psiCHECK-2-TERT plasmid and assistance with luciferase assays. We thank Dr. Nina Ripin and Dr. Fred Damberger for critical reading of the manuscript. NMR was carried out at the Biomolecular NMR Spectroscopy Platform BNSP of the ETH Zurich. This work was supported by the Promedica Foundation (to M.M.D.) and the Swiss National Science Fund SNF (120\% Support Grant to M.M.D., NCCR RNA biology \& disease and SNF grants 31003A_149921 and 31003A_170130 to F.H.-T.A., 31003A_173120 to C.C.).

\section{Author Contributions}

M.M.D., F.H.-T.A. and C.C. designed the experiments and wrote the paper. M.M.D. prepared samples, solved the structure and ran ITC experiments. H.W. performed luciferase, RIP and qPCR assays. T.K. prepared mutants and samples. F.E.L designed and performed the RRM2 titration experiments. C.v.S 
prepared mutants. U.P. synthesized selectively labeled RNA oligos. M.M.D., F.H.-T.A. H.W. and C.C. analyzed data. F.H.-T.A., J.H. and C.C. provided funding and resources.

\section{References}

Afroz T, Cienikova Z, Cléry A. 2015. One, Two, Three, Four! How Multiple RRMs Read the Genome Sequence. Methods Enzymol 558: 235-278.

Afroz T, Skrisovska L, Belloc E, Guillen-Boixet J, Mendez R, Allain FH-T. 2014. A fly trap mechanism provides sequence-specific RNA recognition by CPEB proteins. Genes Dev 28: 1498-1514.

Beaudoin J-D, Novoa EM, Vejnar CE, Yartseva V, Takacs CM, Kellis M, Giraldez AJ. 2018. Analyses of mRNA structure dynamics identify embryonic gene regulatory programs. Nat Struct Mol Biol 25: $677-686$

Case DA, Darden TA, Cheatham TE, Simmerling CL, Wang J, Duke RE, Luo R, Walker RC, Zhang W, Merz KM, et al. 2012. Amber 12. Univ. California, San Francisco

Cavanagh J, Fairbrother WJ, Palmer AG, Skelton NJ, Rance M. 2007. Protein NMR Spectroscopy. Elsevier Inc.

Chen C-Y, Gherzi R, Ong S-E, Chan EL, Raijmakers R, Pruijn GJM, Stoecklin G, Moroni C, Mann M, Karin M. 2001. AU Binding Proteins Recruit the Exosome to Degrade ARE-Containing mRNAs. Cell 107: 451-464.

Chou C-F, Mulky A, Maitra S, Lin W-J, Gherzi R, Kappes J, Chen C-Y. 2006. Tethering KSRP, a decay-promoting AU-rich element-binding protein, to mRNAs elicits mRNA decay. Mol Cell Biol 26: 3695-706.

Cieniková Z, Damberger FF, Hall J, Allain FH-T, Maris C. 2014. Structural and Mechanistic Insights into Poly(uridine) Tract Recognition by the hnRNP C RNA Recognition Motif. J Am Chem Soc 136: 14536-14544.

Cléry A, Blatter M, Allain FH-T. 2008. RNA recognition motifs: boring? Not quite. Curr Opin Struct Biol 18: $290-298$

Cléry A, Sinha R, Anczukow O, Corrionero A, Moursy A, Daubner GM, Valcarcel J, Krainer AR, Allain FH-T. 2013. Isolated pseudo-RNA-recognition motifs of SR proteins can regulate splicing using a noncanonical mode of RNA recognition. Proc Natl Acad Sci.

Corbett AH. 2018. Post-transcriptional regulation of gene expression and human disease. Curr Opin Cell Biol 52: 96-104.

Dang W, Muto Y, Inoue M, Kigawa T, Shirouzu M, Terada T, Yokoyama S. 2006. Solution structure of the RRM domain of unnamed protein product. PDB ID 2DIS.

Delaglio F, Grzesiek S, Vuister G, Zhu G, Pfeifer J, Bax A. 1995. NMRPipe: A multidimensional spectral processing system based on UNIX pipes. J Biomol NMR 6: 277-293.

Deo RC, Bonanno JB, Sonenberg N, Burley SK. 1999. Recognition of Polyadenylate RNA by the Poly(A)-Binding Protein. Cell 98: 835-845.

Dezso Z, Nikolsky Y, Sviridov E, Shi W, Serebriyskaya T, Dosymbekov D, Bugrim A, Rakhmatulin E, Brennan R, Guryanov A, et al. 2008. A comprehensive functional analysis of tissue specificity of human gene expression. BMC Bio/ 6: 49.

Dominguez C, Fisette J-F, Chabot B, Allain FH-T. 2010. Structural basis of G-tract recognition and encaging by hnRNP F quasi-RRMs. Nat Struct Mol Biol 17: 853-861.

Dominguez D, Freese P, Alexis MS, Su A, Hochman M, Palden T, Bazile C, Lambert NJ, Van Nostrand EL, Pratt GA, et al. 2018. Sequence, Structure, and Context Preferences of Human RNA Binding Proteins. Mol Cell 70: 854-867.e9.

Gerstberger S, Hafner M, Ascano M, Tuschl T. 2014a. Evolutionary Conservation and Expression of Human RNA-Binding Proteins and Their Role in Human Genetic Disease. In Systems Biology of 
RNA Binding Proteins. Advances in Experimental Medicine and Biology, vol 825. (ed. G. Yeo), pp. 1-55, Springer, New York, NY

Gerstberger S, Hafner M, Tuschl T. 2014b. A census of human RNA-binding proteins. Nat Rev Genet 15: 829-845.

Goudarzi M, Banisch TU, Mobin MB, Maghelli N, Tarbashevich K, Strate I, van den Berg J, Blaser H, Bandemer S, Paluch E, et al. 2012. Identification and Regulation of a Molecular Module for BlebBased Cell Motility. Dev Cell 23: 210-218.

Gross-Thebing T, Yigit S, Pfeiffer J, Reichman-Fried M, Bandemer J, Ruckert C, Rathmer C, Goudarzi M, Stehling M, Tarbashevich K, et al. 2017. The Vertebrate Protein Dead End Maintains Primordial Germ Cell Fate by Inhibiting Somatic Differentiation. Dev Cell 43: 704-715.e5.

Güntert P, Buchner L. 2015. Combined automated NOE assignment and structure calculation with CYANA. J Biomol NMR 62: 453-471.

Handa N, Nureki O, Kurimoto K, Kim I, Sakamoto H, Shimura Y, Muto Y, Yokoyama S. 1999. Structural basis for recognition of the tra mRNA precursor by the Sex-lethal protein. Nature 398: 579-585.

Herrmann T, Güntert P, Wüthrich K. 2002a. Protein NMR structure determination with automated NOE-identification in the NOESY spectra using the new software ATNOS. J Biomol NMR 24: 171-89.

Herrmann T, Güntert P, Wüthrich K. 2002b. Protein NMR Structure Determination with Automated NOE Assignment Using the New Software CANDID and the Torsion Angle Dynamics Algorithm DYANA. J Mol Biol 319: 209-227.

Hobor F, Dallmann A, Ball NJ, Cicchini C, Battistelli C, Ogrodowicz RW, Christodoulou E, Martin SR, Castello A, Tripodi M, et al. 2018. A cryptic RNA-binding domain mediates Syncrip recognition and exosomal partitioning of miRNA targets. Nat Commun 9: 831.

Kanaar R, Lee AL, Rudner DZ, Wemmer DE, Rio DC. 1995. Interaction of the sex-lethal RNA binding domains with RNA. EMBO J 14: 4530-4539.

Kay LE, Torchia DA, Bax A. 1989. Backbone dynamics of proteins as studied by nitrogen-15 inverse detected heteronuclear NMR spectroscopy: application to staphylococcal nuclease. Biochemistry 28: 8972-8979.

Kedde M, Strasser MJ, Boldajipour B, Oude Vrielink JAF, Slanchev K, le Sage C, Nagel R, Voorhoeve PM, van Duijse J, Ørom UA, et al. 2007. RNA-binding protein Dnd1 inhibits microRNA access to target mRNA. Cell 131: 1273-86.

Kelley LA, Mezulis S, Yates CM, Wass MN, Sternberg MJE. 2015. The Phyre2 web portal for protein modeling, prediction and analysis. Nat Protoc 10: 845-858.

Kibbe WA. 2007. OligoCalc: an online oligonucleotide properties calculator. Nucleic Acids Res 35 : W43-6.

Laskowski R, Rullmann JA, MacArthur M, Kaptein R, Thornton J. 1996. AQUA and PROCHECK-NMR: Programs for checking the quality of protein structures solved by NMR. J Biomol NMR 8: 477486.

Lee W, Tonelli M, Markley JL. 2015. NMRFAM-SPARKY: enhanced software for biomolecular NMR spectroscopy. Bioinformatics 31: 1325-1327.

Licatalosi DD. 2016. Roles of RNA-binding proteins and post-transcriptional regulation in driving male germ cell development in the mouse. In Advances in Experimental Medicine and Biology, Vol. 907 of, pp. 123-151, Springer

Loughlin FE, Lukavsky PJ, Kazeeva T, Reber S, Hock EM, Colombo M, Von Schroetter C, Pauli P, Cléry A, Mühlemann O, et al. 2019. The Solution Structure of FUS Bound to RNA Reveals a Bipartite Mode of RNA Recognition with Both Sequence and Shape Specificity. Mol Cell 73: 490504.

Lukavsky PJ, Daujotyte D, Tollervey JR, Ule J, Stuani C, Buratti E, Baralle FE, Damberger FF, Allain FH-T. 2013. Molecular basis of UG-rich RNA recognition by the human splicing factor TDP-43. Nat Struct Mol Biol 20: 1443-1449.

Lykke-Andersen J, Wagner E. 2005. Recruitment and activation of mRNA decay enzymes by two 
ARE-mediated decay activation domains in the proteins TTP and BRF-1. Genes Dev 19: 35161.

Marchler-Bauer A, Bo Y, Han L, He J, Lanczycki CJ, Lu S, Chitsaz F, Derbyshire MK, Geer RC, Gonzales NR, et al. 2017. CDD/SPARCLE: functional classification of proteins via subfamily domain architectures. Nucleic Acids Res 45: D200-D203.

Masliah G, Barraud P, Allain FH-T. 2013. RNA recognition by double-stranded RNA binding domains: a matter of shape and sequence. Cell Mol Life Sci 70: 1875-95.

Mei W, Jin Z, Lai F, Schwend T, Houston DW, King M Lou, Yang J. 2013. Maternal Dead-End1 is required for vegetal cortical microtubule assembly during Xenopus axis specification. Development 140: 2334-44.

Moursy A, Allain FH-T, Cléry A. 2014. Characterization of the RNA recognition mode of hnRNP G extends its role in SMN2 splicing regulation. Nucleic Acids Res 42: 6659-72.

Notredame C, Higgins DG, Heringa J. 2000. T-coffee: a novel method for fast and accurate multiple sequence alignment. J Mol Biol 302: 205-217.

Oberstrass FC, Auweter SD, Erat M, Hargous Y, Henning A, Wenter P, Reymond L, Amir-Ahmady B, Pitsch S, Black DL, et al. 2005. Structure of PTB bound to RNA: specific binding and implications for splicing regulation. Science 309: 2054-7

Peng SS, Chen CY, Shyu AB. 1996. Functional characterization of a non-AUUUA AU-rich element from the c-jun proto-oncogene mRNA: evidence for a novel class of AU-rich elements. Mol Cell Biol 16: 1490-9.

Ramsköld D, Wang ET, Burge CB, Sandberg R. 2009. An Abundance of Ubiquitously Expressed Genes Revealed by Tissue Transcriptome Sequence Data ed. L.J. Jensen. PLoS Comput Biol 5: e1000598.

Ripin N, Boudet J, Duszczyk MM, Hinniger A, Faller M, Krepl M, Gadi A, Schneider RJ, Šponer J, Meisner-Kober NC, et al. 2019. Molecular basis for AU-rich element recognition and dimerization by the HuR C-terminal RRM. Proc Natl Acad Sci 116: 2935-2944.

Robert X, Gouet P. 2014. Deciphering key features in protein structures with the new ENDscript server. Nucleic Acids Res 42: W320-W324.

Rückert M, Otting G. 2000. Alignment of biological macromolecules in novel nonionic liquid crystalline media for NMR experiments. J Am Chem Soc 122: 7793-7797.

Ruthig VA, Friedersdorf MB, Garness JA, Munger SC, Bunce C, Keene JD, Capel B. 2019. The RNABinding Protein DND1 Acts Sequentially as a Negative Regulator of Pluripotency and a Positive Regulator of Epigenetic Modifiers Required for Germ Cell Reprogramming. Development 146: $\operatorname{dev} 175950$

Ryter JM, Schultz SC. 1998. Molecular basis of double-stranded RNA-protein interactions: structure of a dsRNA-binding domain complexed with dsRNA. EMBO J 17: 7505-13.

Salzmann M, Pervushin K, Wider G, Senn H, Wuthrich K. 2002a. TROSY in triple-resonance experiments: New perspectives for sequential NMR assignment of large proteins. Proc Natl Acad Sci 95: 13585-13590

Salzmann M, Pervushin K, Wüthrich K, Wider G, Senn H. 2002b. TROSY-type Triple-Resonance Experiments for Sequential NMR Assignments of Large Proteins. J Am Chem Soc 121: 844-848.

Seydoux G, Braun RE. 2006. Pathway to Totipotency: Lessons from Germ Cells. Cell 127: 891-904.

Shen Y, Delaglio F, Cornilescu G, Bax A. 2009. TALOS+: a hybrid method for predicting protein backbone torsion angles from NMR chemical shifts. J Biomol NMR 44: 213-223.

Singh R, Valcárcel J. 2005. Building specificity with nonspecific RNA-binding proteins. Nat Struct Mol Biol 12: 645-653.

Slanchev K, Stebler J, Goudarzi M, Cojocaru V, Weidinger G, Raz E. 2009. Control of Dead end localization and activity--implications for the function of the protein in antagonizing miRNA function. Mech Dev 126: 270-7.

Studier FW. 2005. Protein production by auto-induction in high density shaking cultures. Protein Expr Purif 41: 207-34. 
Suzuki A, Igarashi K, Aisaki K -i., Kanno J, Saga Y. 2010. NANOS2 interacts with the CCR4-NOT deadenylation complex and leads to suppression of specific RNAs. Proc Natl Acad Sci 107: 3594-3599.

Suzuki A, Niimi Y, Shinmyozu K, Zhou Z, Kiso M, Saga Y. 2016. Dead end1 is an essential partner of NANOS2 for selective binding of target RNAs in male germ cell development. EMBO Rep 17: 37-46.

Suzuki A, Saba R, Miyoshi K, Morita Y, Saga Y. 2012. Interaction between NANOS2 and the CCR4NOT Deadenylation Complex Is Essential for Male Germ Cell Development in Mouse ed. A.J. Cooney. PLoS One 7: e33558.

Teplova M, Song J, Gaw HY, Teplov A, Patel DJ. 2010. Structural Insights into RNA Recognition by the Alternate-Splicing Regulator CUG-Binding Protein 1. Structure 18: 1364-1377.

Tyler RC, Sreenath HK, Singh S, Aceti DJ, Bingman CA, Markley JL, Fox BG. 2005. Auto-induction medium for the production of [U-15N]- and [U-13C, U-15N]-labeled proteins for NMR screening and structure determination. Protein Expr Purif 40: 268-278.

Vogt M, Taylor V. 2013. Cross-linked RNA Immunoprecipitation. BIO-PROTOCOL 3.

Wang X, Tanaka Hall TM. 2001. Structural basis for recognition of AU-rich element RNA by the HuD protein. Nat Struct Biol 8: 141-145.

Webster MW, Stowell JA, Passmore LA. 2019. RNA-binding proteins distinguish between similar sequence motifs to promote targeted deadenylation by Ccr4-Not. Elife 8.

Weidinger G, Stebler J, Slanchev K, Dumstrei K, Wise C, Lovell-Badge R, Thisse C, Thisse B, Raz E. 2003. dead end, a Novel Vertebrate Germ Plasm Component, Is Required for Zebrafish Primordial Germ Cell Migration and Survival. Curr Biol 13: 1429-1434.

Wenter P, Reymond L, Auweter SD, Allain FH-T, Pitsch S. 2006. Short, synthetic and selectively 13Clabeled RNA sequences for the NMR structure determination of protein-RNA complexes. Nucleic Acids Res 34: e79.

Wu X, Brewer G. 2012. The regulation of mRNA stability in mammalian cells: 2.0. Gene 500: 10-21.

Yamaji M, Jishage M, Meyer C, Suryawanshi H, Der E, Yamaji M, Garzia A, Morozov P, Manickavel S, McFarland HL, et al. 2017. DND1 maintains germline stem cells via recruitment of the CCR4NOT complex to target mRNAs. Nature 543: 568-572.

Youngren KK, Coveney D, Peng X, Bhattacharya C, Schmidt LS, Nickerson ML, Lamb BT, Deng JM, Behringer RR, Capel B, et al. 2005. The Ter mutation in the dead end gene causes germ cell loss and testicular germ cell tumours. Nature 435: 360-364.

Zhu G, Xia Y, Nicholson LK, Sze KH. 2000. Protein Dynamics Measurements by TROSY-Based NMR Experiments. J Magn Reson 143: 423-426. 


\section{Figures and legends}

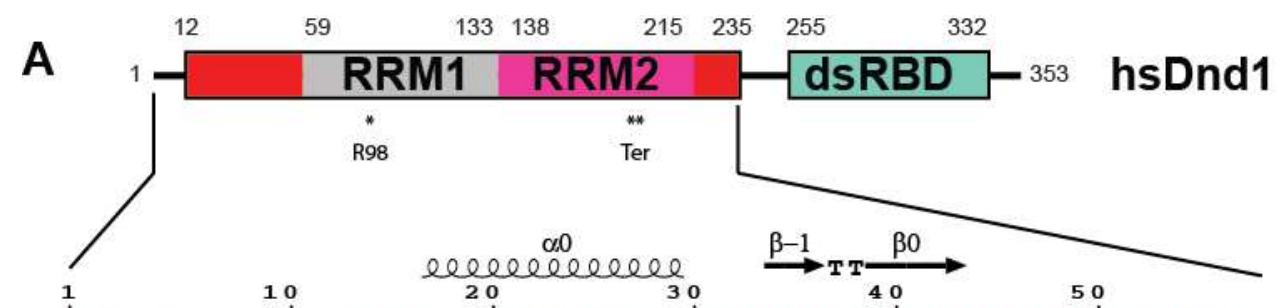

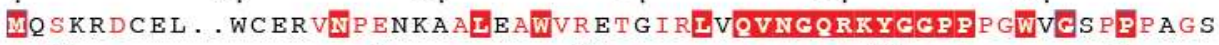

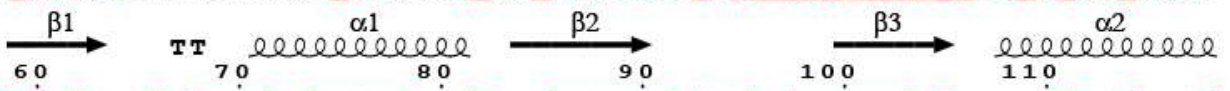

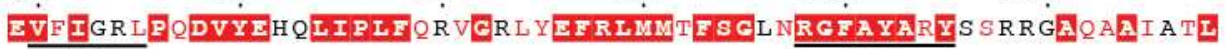

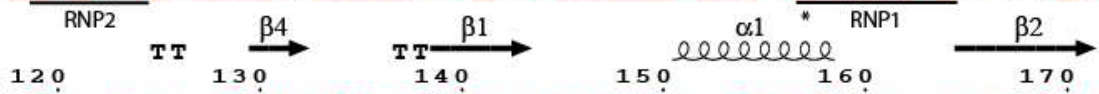

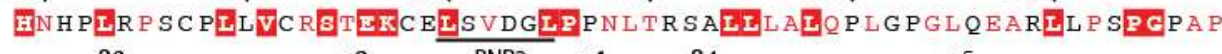

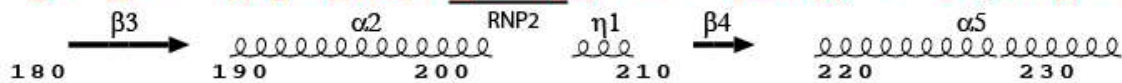

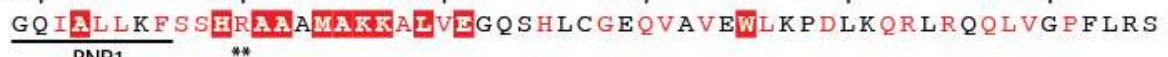
RNP1 Ter

B
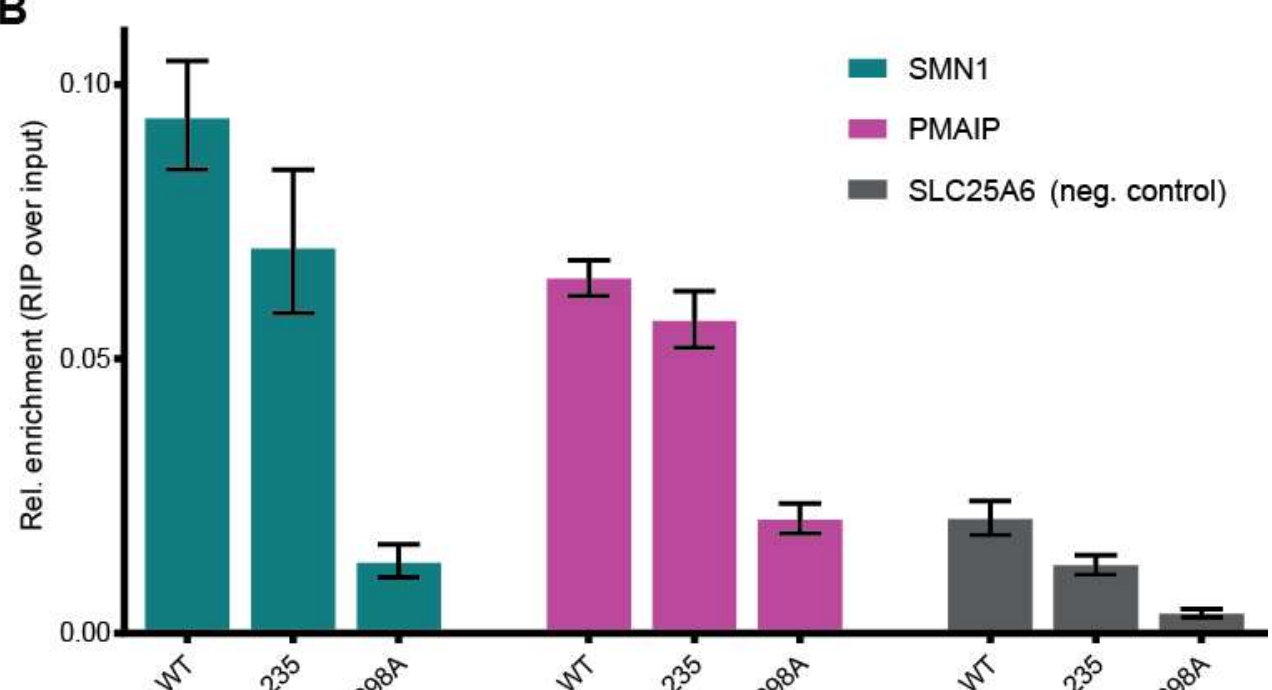


\section{Figure 1. DND1 binds RNA targets mainly through its RRMs}

\section{A) Domain structure of DND1 and sequence of the N-terminal part of the human protein} (Uniprot Q8IYX4) ending at the C-terminus of the tandem RRM construct used for structure determination in this work (12-235). RRM1 in grey, RRM2 in pink, N- and C-terminal conserved extensions in red, dsRBD in green. The dsRBD-truncation mutant 1-235 used in our RIP assay ends after the extension of RRM2. Red coloring in sequence indicates high conservation as described in Fig. S2. Secondary structure elements as found in our structure are indicated above the sequence. The RRM-canonical RNA binding RNP sequences are underlined below. R98 in RNP1 that was mutated for the RIP assay is indicated with one asterix. The Ter truncation at R190 is indicated with a double asterix and 'Ter'. See also Figs. S1 and S2. B) RNA Immunoprecipitation from HEK293T cells transiently expressing FLAG-tagged DND1 or its mutants followed by qPCR using primers for published DND1 targets and a negative control (Table S1). Technical triplicate of a representative plot of three independent experiments is presented as relative enrichment over the input $\left(2^{-\Delta \mathrm{Ct}}\right) . \Delta \mathrm{Ct}$ is an average of (Ct $[R I P]-(C t$ [Input]) of technical triplicates with SD $<0.4$. Error bars represent SD $(\Delta \mathrm{Ct})$. Results from two other independent RIP experiments are shown in Fig. S3A. DND1 and mutants are well expressed in HEK293T cell culture (Fig. S3B). 

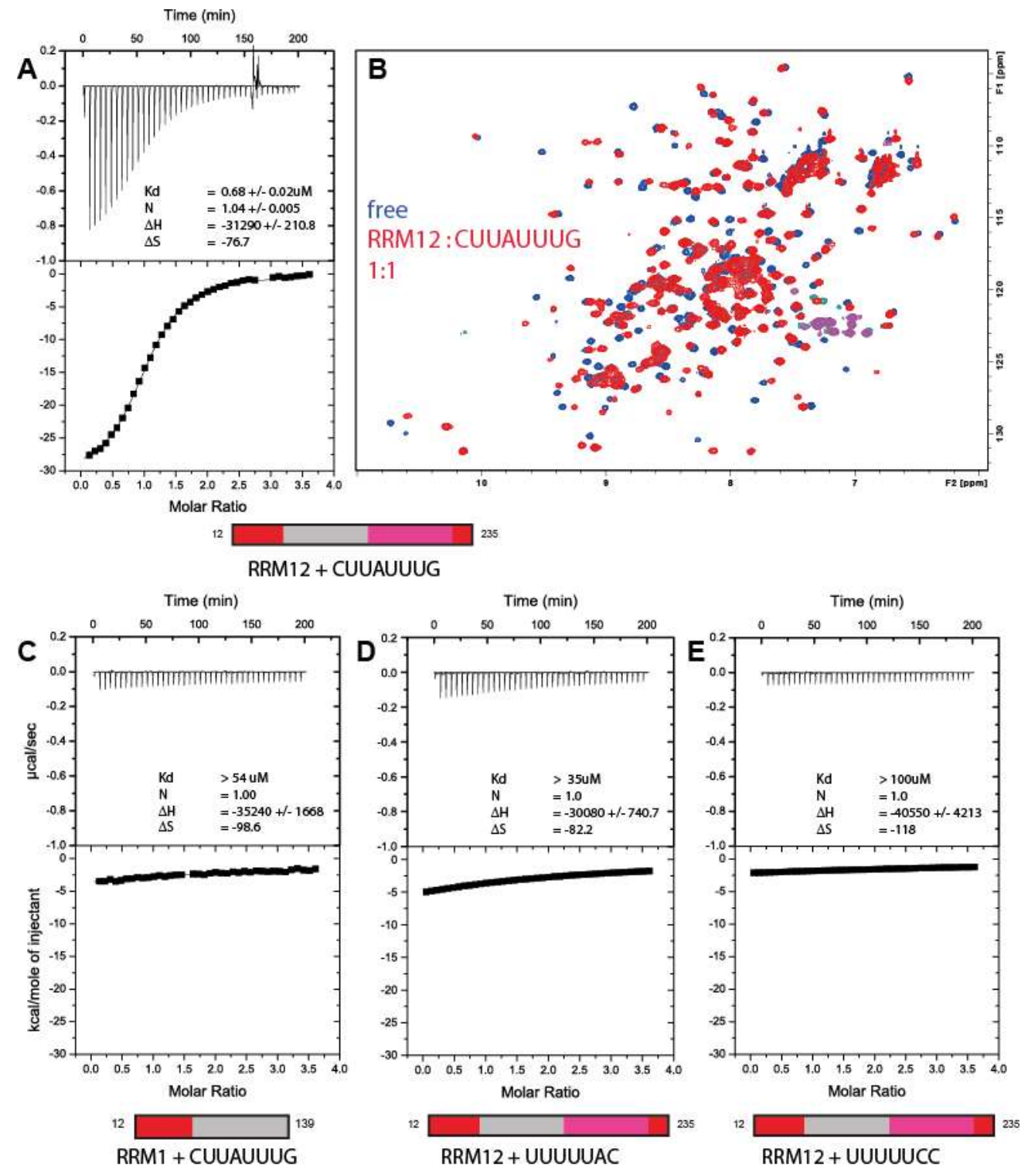

Figure 2. Cooperative binding of DND1's tandem RRMs to AU-rich RNA

A) ITC measurement of DND1's tandem RRMs domain titrated with CUUAUUUG RNA. N = 1.04 $+/-0.005 ; \mathrm{K}_{\mathrm{D}}=0.68+/-0.02 \mathrm{uM} ; \Delta \mathrm{H}=-31.3+/-0.2 \mathrm{kcal} / \mathrm{mol} ;-\mathrm{T} \Delta \mathrm{S}=22.9 \mathrm{kcal} / \mathrm{mol}$. B) overlay of two 1H-15N HSQC spectra of the free DND1 tandem RRMs (in blue) and a 1:1 complex with CUUAUUUG RNA (in red) demonstrates cooperative RNA binding. NMR conditions: Protein concentration $0.2 \mathrm{mM}, 298 \mathrm{~K}, 750 \mathrm{mHz}$. NMR/ITC buffer: 100mM Potassium Phosphate pH 6.6, $1 \mathrm{mM}$ DTT C) ITC measurement of DND1's extended RRM1 titrated with CUUAUUUG ( $N=1$ (set); $K_{D}>$ $54 \mathrm{uM} ; \Delta \mathrm{H}=-35+/-2 \mathrm{kcal} / \mathrm{mol} ;-\mathrm{T} \Delta \mathrm{S}=29.4 \mathrm{kcal} / \mathrm{mol}) \mathrm{D})$ ITC measurement of DND1's tandem RRMs titrated with UUUUUAC ( $\mathrm{N}=1$ (set); $\mathrm{K}_{\mathrm{D}}>35 \mathrm{uM} ; \Delta \mathrm{H}=-30.1+/-0.7 \mathrm{kcal} / \mathrm{mol} ;-\mathrm{T} \Delta \mathrm{S}=24.5$ $\mathrm{kcal} / \mathrm{mol}$ ) and E) DND1's tandem RRMs domain titrated with UUUUUCC ( $\mathrm{N}=1$ (set); $\mathrm{K}_{\mathrm{D}}>100 \mathrm{uM}$; $\Delta \mathrm{H}=-41+/-4 \mathrm{kcal} / \mathrm{mol} ;-\mathrm{T} \Delta \mathrm{S}=35 \mathrm{kcal} / \mathrm{mol})$. See also Fig. $\mathrm{S} 4$ and Table S2. 
A

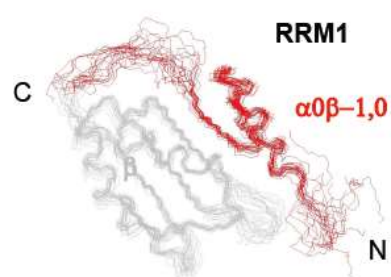

C

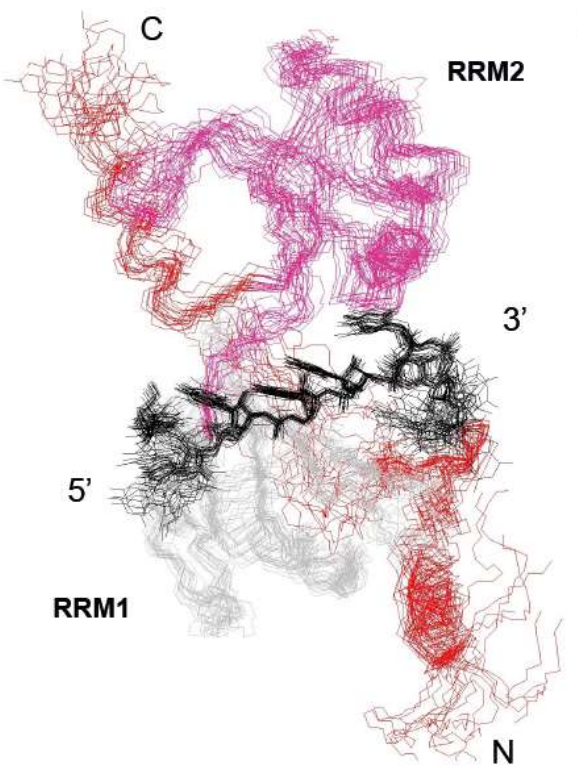

B
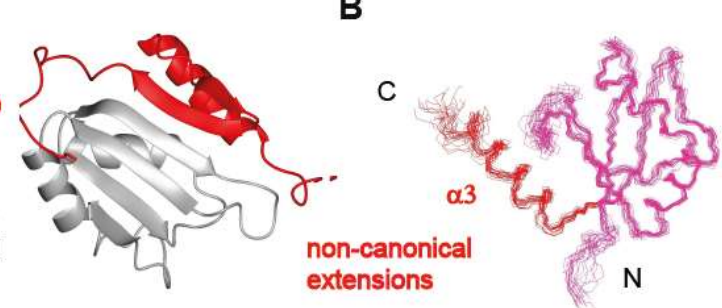

RRM2

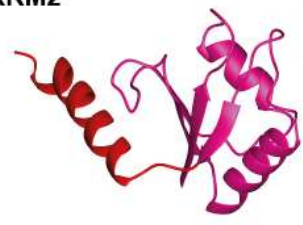

D

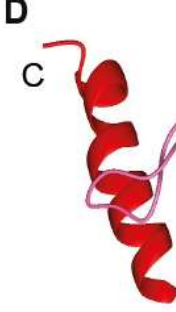

RRM1

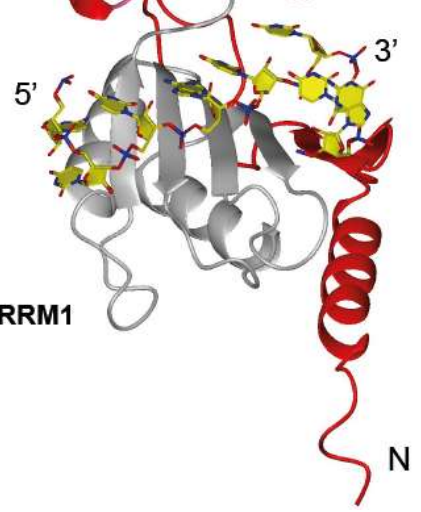

E

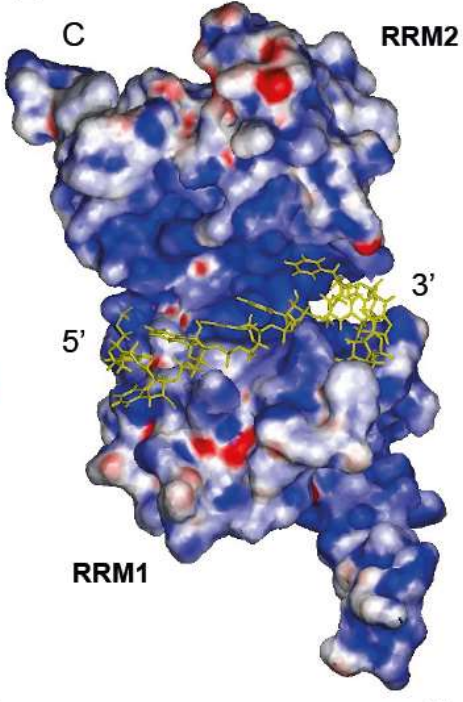

$\mathrm{N}$

Figure 3. Solution structures of DND1's tandem RRMs bound to CUUAUUUG RNA

A) Ensemble of 20 superimposed lowest energy conformers. RRM1 in grey, RRM2 in pink, conserved $\mathrm{N}$ - and $\mathrm{C}$-terminal extensions in red. RNA in black. B) Superimposed 20 lowest energy conformers and representative structures for RRM1 and C) RRM2 within the tandem RRM-RNA complex. D) Representative structure, color coding as in A, RNA in yellow E) Electrostatic surface potential plot shows the RNA is buried in a positively charged cleft between the RRMs. See also Fig. S5 and Table S3. 
A
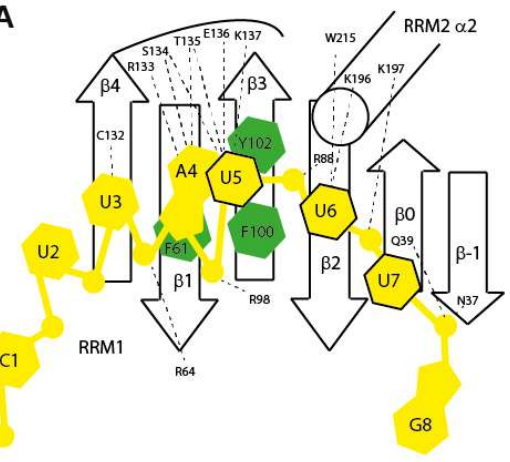

B

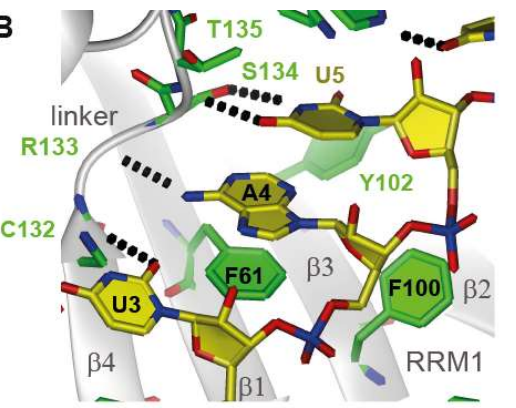

D $v 4$ C 102 RRM2
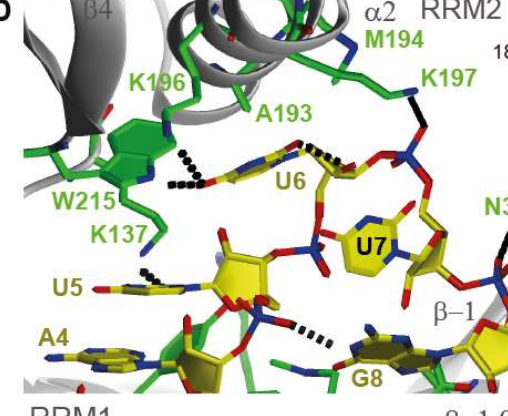

RRM1
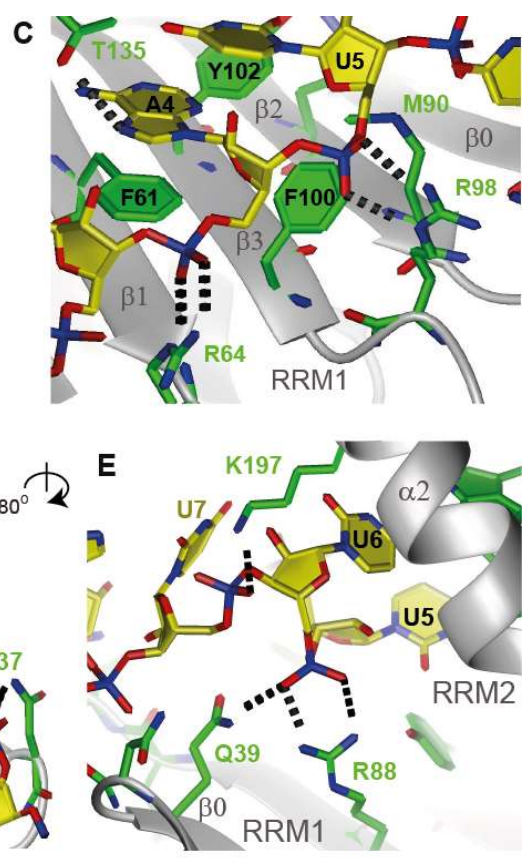

Figure 4. Intermolecular contacts between the DND1 tandem RRMs and the CUUAUUUG RNA A) schematic view of protein-RNA interactions $B$ ) $U_{3}, A_{4}$ and $U_{5}$ base moieties $C$ ) $A_{4}$ and $U_{5}$ backbone $D$ ) $U_{5}, U_{6}$, and $U_{7}$ binding to the interdomain linker and the RRM2 binding pocket. $G_{8}$ binding to the eRRM1 $\beta$-hairpin extension E) Cooperative binding by RRM1 and 2 of the $U_{6}$ and $U_{7}$ phosphate backbone, seen from the back of the molecule. Protein sidechains in green, RNA in yellow. Hydrogen-bonds in dots. See also Fig. S7. 

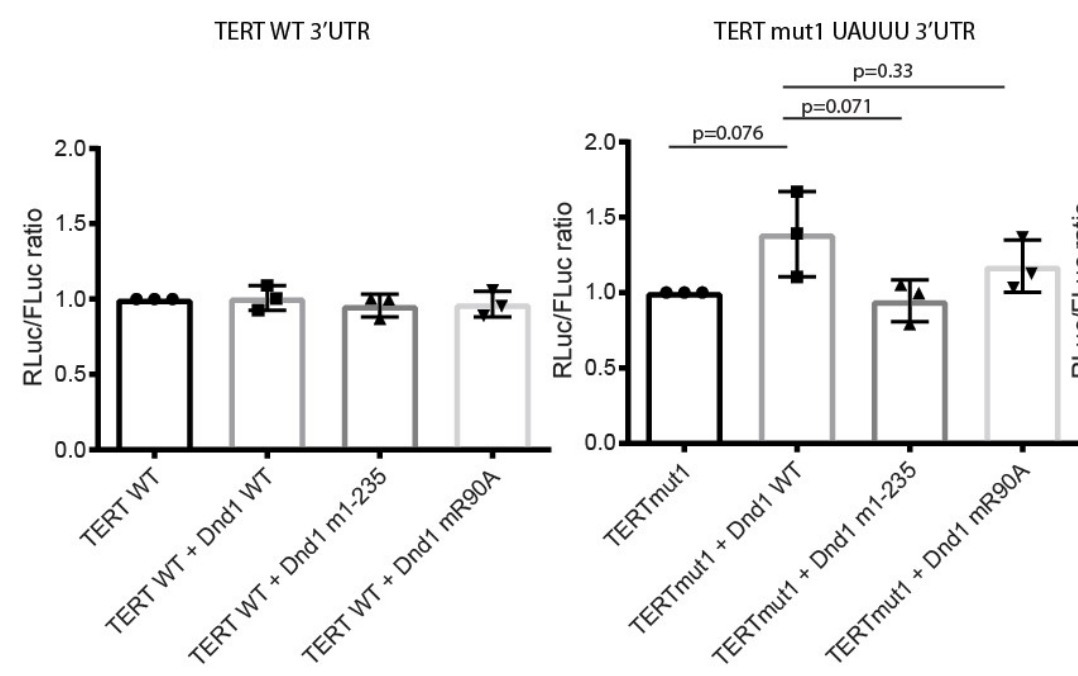

TERT mut2 UAUUUUUUUUAUUU 3'UTR

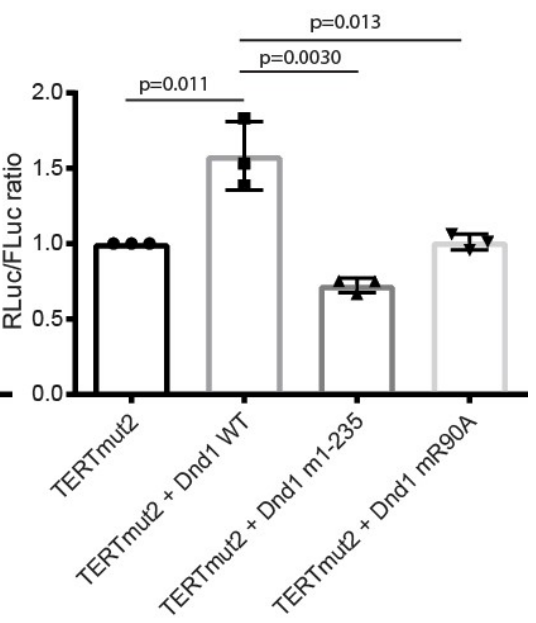

Figure 5 Introduction of an AU-rich motif into a UTR is sufficient, RNA binding by the tandem RRMs is not enough for target stabilization by DND1

A wild-type TERT-UTR psiCHECK2 luciferase construct or the same construct with introduction of a single UAUUU or double UAUUUUUUUUAUUU DND1 tandem RRM target site, and either wild type or mutant FLAG-tagged DND1 were transfected into HEK293T. Relative luciferase activity is the ratio between Renilla control and firefly luciferases, adjusted to 1 for $100 \%$. The results are represented as means and SD from three independent experiments. p-values from two-tailed Welch's t-test. Immunostaining with anti-FLAG antibody in Fig. S3B shows that DND1 and all mutants are well expressed in HEK293T cells. See also Fig. S8. 

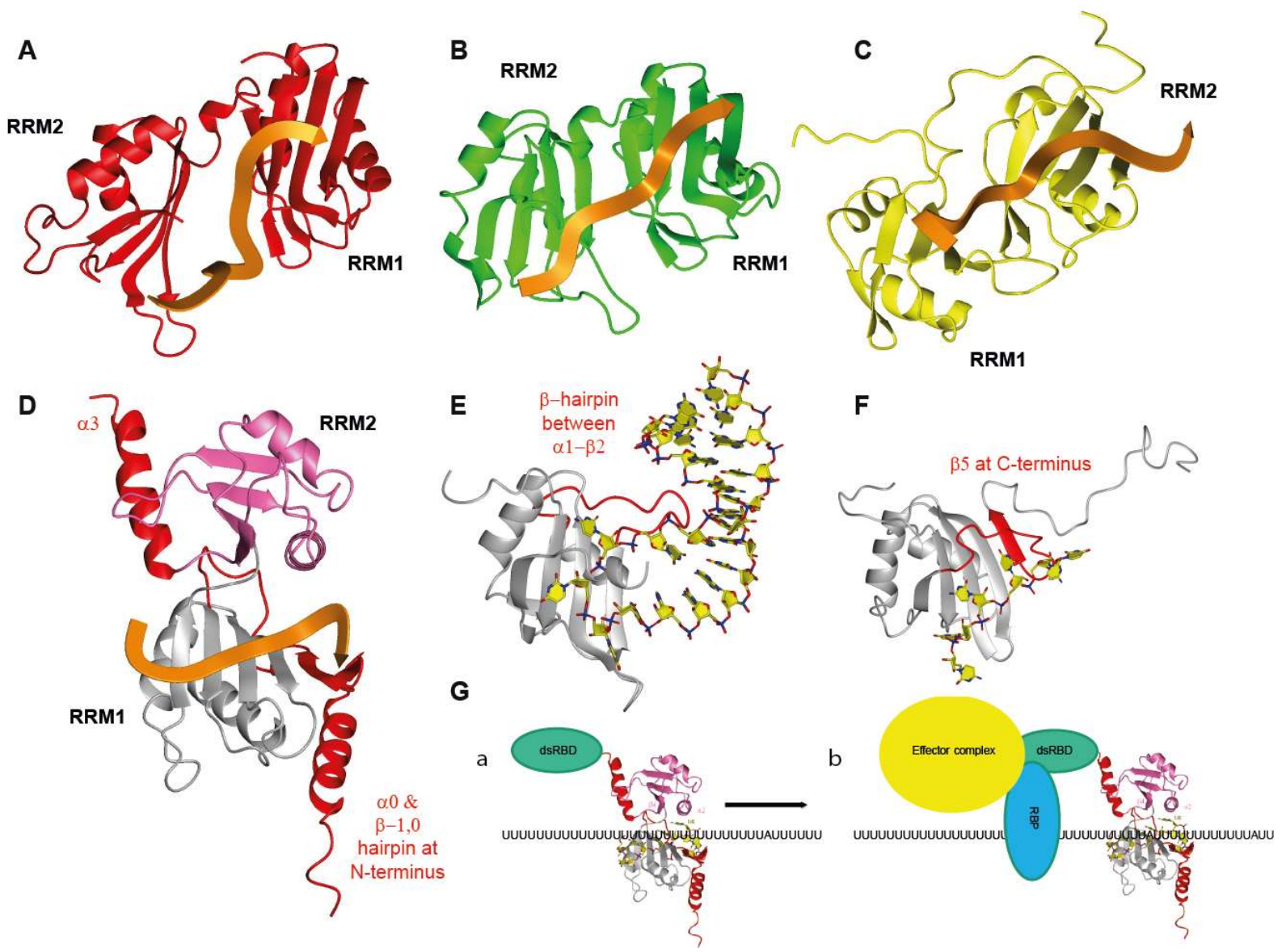

Figure 6. Structural comparison of tandem RRM-RNA complexes (A-D), RRMs using structural extensions to the canonical RRM fold to increase affinity to their RNA targets (D-F) and model of DND1 action mechanism

A) The N-terminal two RRMs of HuD bound to AU-rich RNA B) The N-terminal two RRMs of PABP bound to poly(A) RNA C) The RRMs of TDP-43 bound to UG-rich RNA D) The RRMs of DND1 bound to AU-rich RNA with extensions to the canonical RRM fold shown in red E) FUS RRM bound to a stem-loop from hnRNPA2/B1 pre-mRNA F) RRM2 of PTB bound to CU-rich RNA G) model of AU-rich mRNA target regulation by DND1. 


\section{Main table and legend}

Table 1: NMR statistics

\begin{tabular}{|c|c|c|}
\hline \multicolumn{3}{|c|}{ Dnd1(12-235):CUUAUUUG } \\
\hline \multicolumn{3}{|c|}{ NMR Restraints } \\
\hline \multicolumn{3}{|l|}{ Distance Restraints } \\
\hline \multirow[t]{6}{*}{ Protein } & intramolecular & 4947 \\
\hline & intraresidual & 942 \\
\hline & sequential $(|i-j|=1)$ & 1313 \\
\hline & medium range $(1<|i-j|<5$ & 1190 \\
\hline & long range $(|i-j|>=5$ & 1423 \\
\hline & hydrogen bonds ${ }^{a}$ & 79 \\
\hline \multirow[t]{6}{*}{ RNA } & intramolecular & 150 \\
\hline & intraresidual & 116 \\
\hline & sequential $(|i-j|=1)$ & 34 \\
\hline & medium range $(1<|i-j|<5)$ & \\
\hline & long range $(|i-j|>=5)$ & \\
\hline & hydrogen bonds & \\
\hline \multirow[t]{3}{*}{ Complex } & intermolecular & 103 \\
\hline & long range $(|i-j|>=5$ & 103 \\
\hline & hydrogen bonds & \\
\hline \multicolumn{3}{|l|}{ Torsion Angles ${ }^{b}$} \\
\hline Protein & backbone & 176 \\
\hline RNA & sugar pucker (DELTA) & \\
\hline \multicolumn{3}{|l|}{ RDCs } \\
\hline Protein & amide $\mathrm{NH}$ & 127 \\
\hline \multicolumn{3}{|c|}{ Energy Statistics $^{c}$} \\
\hline \multicolumn{3}{|c|}{ Average distance constraint violations } \\
\hline \multirow{2}{*}{\multicolumn{2}{|c|}{$\begin{array}{l}0.3-0.4 \AA \\
>0.4 \AA\end{array}$}} & $10.3+/-2.5$ \\
\hline & & $5.5+/-2.0$ \\
\hline \multicolumn{2}{|c|}{ Maximal (A) } & $0.66+/-0.14$ \\
\hline \multicolumn{3}{|c|}{ Average angle constraint violations } \\
\hline \multicolumn{2}{|c|}{$>5$ degree } & $3.0+/-1.2$ \\
\hline \multicolumn{2}{|c|}{ Maximal (degree) } & $9.0+/-4.5$ \\
\hline \multicolumn{3}{|c|}{ Average RDC violations } \\
\hline \multicolumn{2}{|c|}{$>5 \mathrm{~Hz}$} & $5.2+/-1.2$ \\
\hline \multicolumn{2}{|l|}{ Maximal $(\mathrm{Hz})$} & $6.1+/-0.9$ \\
\hline \multicolumn{2}{|c|}{ RDC correlation coefficient } & $0.96+/-0.01$ \\
\hline \multicolumn{2}{|c|}{$\mathrm{Q}=\operatorname{rms}($ Dcalc-Dobs $) / \mathrm{rms}($ Dobs $)(\%)$} & $30.7+/-2.2$ \\
\hline \multicolumn{2}{|c|}{ Q normalized by tensor } & $17.9+/-1.5$ \\
\hline Mean AMBER Viol & & \\
\hline Constraint (kcal n & & $297.5+/-21.9$ \\
\hline Distance $(\mathrm{kcal} \mathrm{mc}$ & & $168.9+/-18.5$ \\
\hline Torsion (kcal mol & & $10.7+/-2.4$ \\
\hline Alignment $(\mathrm{kcal} \mathrm{m}$ & & $104.4+/-9.3$ \\
\hline Mean AMBER Ene & $\left.\mathrm{mol}^{-1}\right)$ & $-7568.9+/-18.5$ \\
\hline Mean Deviation fro & ovalent geometry & \\
\hline Bond Length $(A)$ & & $0.0041+/-0.0000$ \\
\hline Bond Angle (degr & & $1.511+/-0.009$ \\
\hline Ramachandran plot & & \\
\hline Residues in most $f$ & egions (\%) & $82.1+/-1.9$ \\
\hline Residues in additic & ved regions (\%) & $15.3+/-2.1$ \\
\hline Residues in generc & ved regions (\%) & $2.0+/-0.8$ \\
\hline Residues in disallo & ns (\%) & $0.6+/-0.5$ \\
\hline RMSD to mean stru & & \\
\hline Protein Dnd1 RRM & & \\
\hline Backbone atoms & & $0.95+/-0.23$ \\
\hline
\end{tabular}




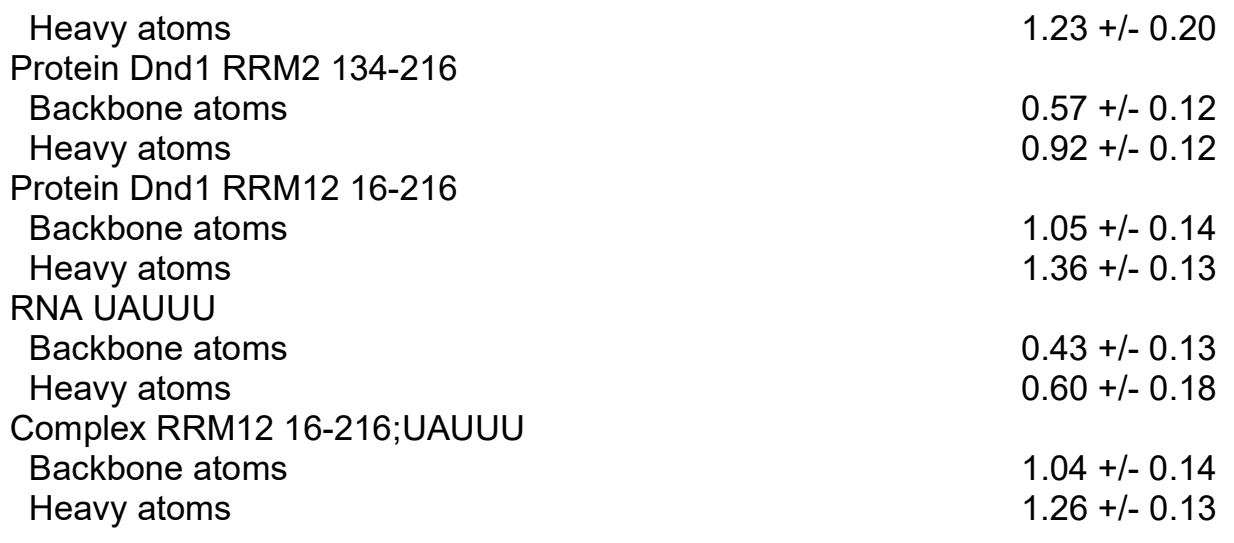

RMSD, root-mean-square deviation

a Hydrogen bond constraints were identified from slow exchanging amide and imino protons in $\mathrm{D}_{2} \mathrm{O}$ b Torsion angle based on TALOS+ predictions; sugar puckers based on homonuclear TOCSY c Dnd1 RRM12, 16-216 Chain ID: A (Sequence Range:12-235); RNA CUUAUUUG: 3-7, Chain ID: B (Sequence Range:1-8)

d Ramachandran plot, as defined by the program Procheck (Laskowski et al. 1996). 


\section{Methods}

\section{REAGENTS \& RESOURCES TABLE}

\begin{tabular}{|c|c|c|}
\hline REAGENT or RESOURCE & SOURCE & IDENTIFIER \\
\hline \multicolumn{3}{|l|}{ Antibodies } \\
\hline FLAG-M2-HRP & Sigma & A8592 \\
\hline \multicolumn{3}{|l|}{ Bacterial and Virus Strains } \\
\hline Top10 competent cells & This study & \\
\hline BL21(DE3) competent cells & This study / Novagen & \\
\hline \multicolumn{3}{|l|}{ Biological Samples } \\
\hline DMEM & Sigma & D6429 \\
\hline FBS & Sigma & F7524 \\
\hline OptiMEM & GIBCO & 31985047 \\
\hline \multicolumn{3}{|l|}{ Chemicals, Peptides, and Recombinant Proteins } \\
\hline TEV protease & In house produced & \\
\hline \multicolumn{3}{|l|}{ Critical Commercial Assays } \\
\hline Clarify ${ }^{\mathrm{TM}}$ Western ECL substrate & BioRad & $170-5061$ \\
\hline Dual-Glow Luciferase Assay System & Promega & E2920 \\
\hline \multicolumn{3}{|l|}{ Deposited Data } \\
\hline Chemical Shifts & BioMagResBank & $x x x$ \\
\hline Structural Ensemble & Protein Data Bank & $x x x$ \\
\hline \multicolumn{3}{|l|}{ Experimental Models: Cell Lines } \\
\hline HEK293T cell line & ATCC & CRL-3216 ${ }^{\mathrm{TM}}$ \\
\hline \multicolumn{3}{|l|}{ Oligonucleotides } \\
\hline CUUAUUUG RNA & Dharmacon & \\
\hline selectively ribose-13C labeled RNA & This study & \\
\hline Oligonucleotides for cloning \& site-directed mutagenesis & Microsynth & Table S1 \\
\hline miRIDIAN miR-221-3p miRNA mimic & Dharmacon & MIMAT0000278 \\
\hline Scrambled miRNA mimic & Dharmacon & $\mathrm{CN}-001000-01-05$ \\
\hline \multicolumn{3}{|l|}{ Recombinant DNA } \\
\hline pET-M11 vector & EMBL & \\
\hline pET-His-TEV & EMBL & \\
\hline psiCHECK2 vector & Promega & \\
\hline pCMV-SPORT6-hsDnd1 source plasmid & Source BioScience & IRATp970F0747D \\
\hline pcFLAG_DNA3.1 & This study / Invitrogen & \\
\hline \multicolumn{3}{|l|}{ Software and Algorithms } \\
\hline NMR data acquisition and processing & Topspin (Bruker) & Version 2.1 \\
\hline NMR data processing and relaxation analysis & NMRPipe & \\
\hline Spectral analysis & NMRFAM-Sparky & Version 1.1412 \\
\hline Structure refinement & AMBER 12 & Ff12SB force field \\
\hline Structure calculation & CYANA & Version 3.98 \\
\hline Peak picking, structure calculation & ATNOS-CANDID & Version 3.1 \\
\hline Statistical analyses & PRISM & Version $6.0 \mathrm{e}$ \\
\hline
\end{tabular}




\section{CONTACT FOR REAGENT AND RESOURCE SHARING}

Further information and requests for resources and reagents should be directed to and will be fulfilled by the Lead Contact, Frédéric Allain (allain@mol.biol.ethz.ch).

\section{EXPERIMENTAL MODEL AND SUBJECT DETAILS}

HEK293T cells were cultured in Dulbecco's Modified Eagle Medium (DMEM, Sigma) containing 10\% fetal bovine serum (FBS, Sigma) including antibiotics $(0.05 \mathrm{mg} / \mathrm{mL}$ of streptomycin, and $50 \mathrm{U} / \mathrm{mL}$ of penicillin (Sigma)) in a humidified incubator (Thermo Scientific Heraeus Series 6000 Incubators, Thermo Scientific) with $5 \% \mathrm{CO}_{2}$ at $37^{\circ} \mathrm{C}$.

\section{METHOD DETAILS}

\section{Protein expression and purification}

DNA fragments encoding human Dnd1 RRM1 (12-139), RRM2 (136-227) or the tandem RRM12 (12235) were PCR amplified from the source plasmid pCMV-SPORT6-hsDnd1, an IMAGE cDNA clone (clone ID MGC:34750; IMAGE: 5172595) purchased from Source BioScience (Nottingham UK) with the primers listed in Table S1. They were cloned into the pET-M11 vector (EMBL) with an N-terminal TEV-cleavable 6xHis-tag between the Ncol and Acc65I restriction sites, using Bbsl instead of Ncol to cut the insert to circumvent insert-internal restriction sites. Protein mutants were obtained by PCRbased site-directed mutagenesis with the pET-M11-RRM12 (12-235) plasmid as a template according to the QuikChange protocol (Stratagene) and the primers listed in Table S1. All protein constructs were expressed in E. coli BL21(DE3) cells (Novagen) in Studier-medium P-5052 supplemented with ${ }^{15} \mathrm{NH}_{4} \mathrm{Cl}$ or $\mathrm{P}-50501$ supplemented with ${ }^{15} \mathrm{NH}_{4} \mathrm{Cl}$ and ${ }^{13} \mathrm{C}$-glycerol (CIL). Precultures were grown in PA-0.5G medium (Studier 2005; Tyler et al. 2005). Random fractionally deuterated protein for recording of triple-resonance spectra for backbone assignment was expressed in $100 \%$ D2O (CIL) in which the media components were directly dissolved. Protein was expressed for $60 \mathrm{~h}$ at $15^{\circ} \mathrm{C}$ in the presence of $100 \mu \mathrm{g} / \mathrm{mL}$ Kanamycin. Cells were harvested by centrifugation at 4 ${ }^{\circ} \mathrm{C}, 15 \mathrm{~min}$ at $2,600 \mathrm{~g}$, and the cell pellet was resuspended in lysis buffer $(20 \mathrm{mM}$ Tris, $\mathrm{pH} 8,1 \mathrm{M}$ $\mathrm{NaCl}, 0.2 \%$ Triton-x-100 (w/v), $10 \mathrm{mM}$ imidazole, and 2 mM 2-mercaptoethanol). Cells were lysed with two freeze-thaw cycles and three passes through the Emulsiflex cell cracker (Avestin). Before 
lysis $0.5 \mathrm{mg} / \mathrm{ml}$ lysozyme, $25 \mathrm{ug} / \mathrm{ml}$ DNAsel and $1 \mathrm{mM}$ Pefabloc SC (Sigma-Aldrich) was added. After centrifugation at $4{ }^{\circ} \mathrm{C}$ for $20 \mathrm{~min}$ at $43,000 \mathrm{~g}$, the cleared supernatant was sterile-filtered and loaded onto $2 \mathrm{~mL}$ Ni-NTA beads (Qiagen), equilibrated with lysis buffer, per liter of bacterial culture. The column was washed with 10 column volumes of lysis buffer, 20 columns of lysis buffer without Triton and 5 column volumes of the same buffer with $30 \mathrm{mM}$ Imidazole, before the protein was eluted with elution buffer (lysis buffer without Triton and with $330 \mathrm{mM}$ imidazole). For cleavage of the His 6 tag, the pooled fractions were dialyzed against lysis buffer $(1 \mathrm{M} \mathrm{NaCl}$ and no imidazole) in the presence of in-house purified TEV protease $\left(1: 100 \mathrm{w} / \mathrm{w}\right.$ TEV:protein) at $4{ }^{\circ} \mathrm{C}$ overnight. Next day the TEV cleavage reaction was reloaded three times over a fresh Ni-NTA column to remove the His6-TEV protease, the His6-tag fusion and contaminating proteins. The proteins were concentrated with Vivaspin 20-mL centrifugal devices with 5,000 or 10,000 MWCO (Sartorius) and buffer-exchanged into NMR buffer over PD-10 gel-filtration columns (GE-healthcare).

\section{RNA samples.}

Unlabeled RNA oligonucleotides were purchased from Dharmacon, deprotected according to the manufacturer's instructions, lyophilized and resuspended twice in water for large-scale protein-RNA complex production or NMR buffer for titrations or ITC (20mM MES pH 6.6, $100 \mathrm{mM} \mathrm{NaCl})$. For the solid phase synthesis of selectively ribose-labeled oligos 2'-O-TOM protected ribonucleoside phosphoramidites and solid supports containing $\left[{ }^{13} \mathrm{C}_{5}\right]$-labeled ribose moieties were synthesized as described, followed by their sequence-specific introduction into the CUUAUUUG oligo (Wenter et al. 2006).

\section{NMR sample preparation of Protein-RNA complexes}

Final protein was analyzed for nucleic acid contamination using $A_{260 n m} / A_{280 n m}$ and concentration was estimated using $A_{280 n m}$ and a theoretical extinction coefficient of $18140 \mathrm{M}^{-1} \mathrm{~cm}^{-1}$ for RRM1, $5930 \mathrm{M}^{-1} \mathrm{~cm}^{-}$

${ }^{1}$ for RRM2 and $23470 \mathrm{M}^{-1} \mathrm{~cm}^{-1}$ for RRM12. RNA concentrations were estimated using OligoCalc (Kibbe 2007). In the final buffer exchange step the RRM constructs were added dropwise to a $10 \%$ molar excess of RNA in the presence of 10ul of Superaseln RNase inhibitor (Ambion) per sample, concentrated and further purified by size exclusion chromatography on a Sephadex 75 10/30 column 
(GE healthcare) in $100 \mathrm{mM} \mathrm{KHPO} / \mathrm{KH}_{2} \mathrm{PO}_{4} \mathrm{pH} 6.6,1 \mathrm{mM}$ DTT. The fractions containing the proteinRNA complex were concentrated to 400-700 uM with Vivaspin 5-mL centrifugal devices with 10,000 MWCO (Sartorius). Before the measurements a 10\% molar excess of RNA was added to saturate the protein as well as $10 \% \mathrm{v} / \mathrm{v} \mathrm{D}_{2} \mathrm{O}$. Complexes were lyophilized before resuspending in $\mathrm{D}_{2} \mathrm{O}$ for NMR experiments that are conducted in deuterated solvent.

\section{Plasmids for cell culture assays}

Total RNA was extracted from cultured human fibroblasts (GM03814, Coriell Institute for Medical Research, USA). 1ug was then used for reverse transcription reaction using Oligo(dT) 18 and M-MuLV Reverse Transcriptase $\mathrm{RNaseH}^{-}$(Finnzymes). The 3'UTR of TERT and fragments corresponding to positions 183-282 (according to Ensembl transcript ENST00000228872) of the 3'UTR of p27 including the predicted miR-221 binding sites were amplified from the cDNA templates using the appropriate primers in table S1 introducing Xhol and Notl restriction sites. The Dnd1 binding site was introduced into the TERT 3'UTR insert using PCR overlap extension using the primers in table S1. 3'UTR PCR products were directionally cloned downstream of the Renilla luciferase open reading frame (ORF) of the psiCHECK2 vector (Promega) that also contains a constitutively expressed firefly luciferase gene, which was used to normalize transfections. Dnd1 fragments encoding the full-length human protein (1353 ) or a dsRBD truncation (1-235) were amplified as described for the protein expression plasmids and cloned BamHI/EcoRI into an in-house modified pcDNA3.1+ plasmid (Invitrogen) with an N-terminal FLAG tag cloned Nhel/HindllI. All plasmids were confirmed by sequencing and deposited at AddGene (www.addgene.org/Frederic_Allain). Plasmids for transfections were prepared using the Nucleobond Xtra midiprep kit (Macherey-Nagel) according to the manufacturer's protocol.

\section{Transfections and Dual luciferase activity analysis}

HEK293T cells were transfected with Lipofectamine 2000 Reagent (Invitrogen) after seeding them 16 hours prior at $70^{\circ} 000$ cells per well (24-well plate) or $2.8 \times 10^{6}$ cells per $10 \mathrm{~cm}$ dish for immunoblotting analysis and RNA immunoprecipitation. For transfections in 24-well plates, Lipofectamine 2000 Reagent was diluted in serum free medium (OptiMEM, GIBCO) and incubated for $5 \mathrm{~min}$ at room temperature. 
Plasmid DNA (0.5 $\mu \mathrm{g}$ per plasmid as indicated) and/or $50 \mathrm{nM}$ final miR-221-3p miRNA mimic (miRIDIAN, Dharmacon) or control mimic was then added, vortexed, and incubated for 20 min at room temperature while cell culture media was exchanged to DMEM containing 10\% FBS without antibiotics. Finally, the transfection complexes were added to the cell culture vessel in a drop wise manner while swirling. Transfection media were changed $6 \mathrm{~h}$ later to regular culture media. Luciferase activity was measured 48 hours after transfection using the Dual-Glow Luciferase Assay System (E2920 Promega, USA) on a GloMax® Discover Multimode Microplate Reader (Promega, USA). The results are represented as means and standard deviation (SD) from three independent experiments.

\section{Immunoblotting analysis of protein expression and antibodies}

Total cellular protein was extracted from $6 \times 10^{5}$ HEK293T cells using a RIPA buffer ( $1 \%$ NP-40, $150 \mathrm{mM}$ $\mathrm{NaCl}, 50 \mathrm{mM}$ Tris- $\mathrm{HCl} \mathrm{pH}$ 8.0, 0.5\% Sodium deoxycholate, 0.5\% SDS) complemented with EDTA-free protease inhibitor cocktail (Roche) followed by brief sonication. Protein concentrations were determined by DC Assay (Bio-Rad). For each sample, $14 \mu \mathrm{g}$ of total cellular protein was separated on $12 \%$ SDSPAGE gels and transferred on PVDF membranes. The following antibody was used: FLAG-M2-HRP (SIGMA, A8592). Immunoblots were developed using the Clarify ${ }^{\mathrm{TM}}$ Western ECL substrate (BioRad) kit and were detected using an imaging system (ChemiDoc ${ }^{\mathrm{TM}}$ MP - BioRad). All membranes were stained using a coomassie blue staining solution to ensure equal loading. The analysis was performed in triplicate.

\section{RNA immunoprecipitation}

The RNA-immunoprecipitation (RIP) procedure was adapted from Vogt and Taylor (Vogt and Taylor 2013). Briefly, subconfluent cells from one $10 \mathrm{~cm}$ dish were harvested 48 hours after transfection, washed in PBS1X, and cross-linked with $1 \%$ formaldehyde. Glycine $(0.125 \mathrm{M}$ final $)$ was added to quench the formaldehyde. Cells were pelleted by centrifugation and washed with PBS1X. Immunoprecipitation (IP) lysis buffer (50 mM HEPES at pH 7.5, 0.4 M NaCl, $1 \mathrm{mM}$ ethylenediaminetetraacetic acid (EDTA), $1 \mathrm{mM}$ DTT, $0.5 \%$ Triton X-100, 10\% glycerol) containing $1 \mathrm{mM} \mathrm{PMSF}$, protease inhibitors (Roche), and RNase inhibitor (Thermo Scientific) was added to the cell pellet. After sonication (Bioruptor, Diagenode), cell lysates were precleared with IP Lysis buffer containing 1\% BSA. $40 \mu$ l of magnetic FLAG-M2 beads 
(SIGMA, M8823) were added to precleared cell lysate and incubated on a rotary wheel at $4{ }^{\circ} \mathrm{C}$ overnight. FLAG-M2 beads were washed with IP Iysis buffer five times and pelleted by centrifugation. RIP buffer (50 mM HEPES at pH 7.5, 0.1 M NaCl, 5 mM EDTA, $10 \mathrm{mM}$ DTT, 0.5\% Triton X-100, 10\% glycerol, $1 \%$ SDS) containing RNase inhibitor was added to the pellet and incubated 1 hour at $70^{\circ} \mathrm{C}$ to reverse the cross-links. After centrifugation, the supernatant was used for RNA extraction using TRIzol reagent (Life technologies) followed by a DNase I treatment and a subsequent reverse transcription with oligo $\mathrm{d}[\mathrm{T}]_{18}$ using the GoScript RT kit (Promega). One-step RT-qPCR was performed using the SYBR FAST Mix optimized for LightCycler 480 (KAPA, KK4611) with primers listed in table S1. The results are presented as relative enrichment over the input $\left(2^{-\Delta C t}\right) . \Delta \mathrm{Ct}$ is an average of $(\mathrm{Ct}[\mathrm{RIP}]-(\mathrm{Ct}$ [Input]) of technical triplicates with SD $<0.4$. Three independent RIP experiments were performed.

\section{NMR data collection and assignments}

All NMR spectra were recorded at 298K on Bruker AVIII600 MHz, AVIII700 MHz, and Avance $900 \mathrm{MHz}$ spectrometers equipped with cryoprobes and a Bruker AVIII750MHz spectrometer using standard NMR experiments if not mentioned otherwise (Cavanagh et al. 2007). The data were processed using Topspin 3.1 (Bruker) and NMR Pipe (Delaglio et al. 1995) and analyzed with NMR-FAM-SPARKY (Lee et al. 2015). Sequence-specific backbone assignments were $93 \%$ complete for non-proline residues and were obtained from 2D ${ }^{1} \mathrm{H}-{ }^{15} \mathrm{~N} H S Q C, 2 \mathrm{D}{ }^{1} \mathrm{H}-{ }^{13} \mathrm{C}-\mathrm{HSQC}, 3 \mathrm{D}{ }^{1} \mathrm{H}-{ }^{15} \mathrm{~N}-\mathrm{NOESY}\left(\mathrm{t}_{\mathrm{mix}}=120 \mathrm{~ms}\right)$ and a suite of 3D TROSY-based backbone experiments (HNCO, HN(CA)CO, HNCA, HN(CO)CA, HNCACB and $\mathrm{HN}(\mathrm{CO}) \mathrm{CACB})\left(\right.$ Salzmann et al. 2002a, 2002b) run on a random fractionally deuterated ${ }^{13} \mathrm{C},{ }^{15} \mathrm{~N}$-labeled (1:1.1) tandem RRM-CUUAUUUG complex. Sidechain protons were assigned to $80 \%$ completeness using 3D ${ }^{1} \mathrm{H}-{ }^{15} \mathrm{~N}-N O E S Y\left(t_{\text {mix }}=120 \mathrm{~ms}\right), 3 \mathrm{D}{ }^{1} \mathrm{H}-{ }^{13} \mathrm{C}-\mathrm{HMQC}-\mathrm{NOESY}\left(\mathrm{t}_{\mathrm{mix}}=70 \mathrm{~ms}\right), 3 \mathrm{D}{ }^{1} \mathrm{H}-{ }^{13} \mathrm{C}-\mathrm{HSQC}-$ aromatic-NOESY ( $\left.\mathrm{t}_{\text {mix }}=80 \mathrm{~ms}\right), 3 \mathrm{D}(\mathrm{H}) \mathrm{CCH}-\left(\mathrm{t}_{\text {mix }}=21.7 \mathrm{~ms}\right)$ and $\mathrm{HC}(\mathrm{C}) \mathrm{H}-\mathrm{TOCSY}\left(\mathrm{t}_{\text {mix }}=23 \mathrm{~ms}\right)$ and 3D $\mathrm{H}(\mathrm{C}) \mathrm{CH}-\mathrm{COSY}$ on a sample of fully protonated ${ }^{13} \mathrm{C},{ }^{15} \mathrm{~N}$-labeled $(1: 1.1)$ tandem RRM-CUUAUUUG complex. Sidechains in the free ${ }^{13} \mathrm{C},{ }^{15} \mathrm{~N}$-labeled RRM2 were assigned using $\mathrm{H}(\mathrm{C})(\mathrm{CCCO}) \mathrm{NH}-\mathrm{TOCSY}$ $\left(t_{\text {mix }}=17.75 \mathrm{~ms}\right)$ and $(\mathrm{H}) \mathrm{C}(\mathrm{CCCO}) \mathrm{NH}-\mathrm{TOCSY}\left(\mathrm{t}_{\text {mix }}=17.75 \mathrm{~ms}\right)$ and transferred to the RRM12CUUAUUUG complex where this was possible. RNA was assigned using the following set of spectra: 2D TOCSY $\left(\mathrm{t}_{\text {mix }}=60 \mathrm{~ms}\right), 2 \mathrm{D}$ NOESY $\left(\mathrm{t}_{\mathrm{mix}}=150 \mathrm{~ms}\right)$ recorded on a 1:1 complex of unlabeled tandem RRM-CUUAUUUG complex. 2D ${ }^{1} \mathrm{H}-{ }^{13} \mathrm{C}-\mathrm{HSQC}$ recorded on 1:1 complexes between unlabeled tandem RRMs and selectively ${ }^{13} \mathrm{C}$ ribose-labeled $C^{*} U U^{*} A U^{*} U U^{*} G$ or $C U^{*} U A^{*} U U^{*} U G^{*} R N A$ where an asterix 
after the nucleotide represents a ${ }^{13} \mathrm{C}$ labeled ribose moiety. 2D F 2 filtered NOESY ( $\mathrm{t}_{\text {mix }}=120 \mathrm{~ms}$ ) and 2D F 1 filtered, $F_{2}$ filtered NOESY recorded on ${ }^{13} \mathrm{C},{ }^{15} \mathrm{~N}$-labeled tandem RRMs in 1:1 complex with 1) unlabeled CUUAUUUG RNA 2) selectively ${ }^{13} \mathrm{C}$ ribose-labeled $C^{*} U U^{*} A U^{*} U U^{*} G$ RNA 3) selectively ${ }^{13} \mathrm{C}$ ribose-labeled $C U^{*} U A^{*} U U^{*} U G^{*}$ RNA. Sugar puckers in the complex were identified from $2 \mathrm{D}{ }^{1} \mathrm{H}-{ }^{1} \mathrm{H}-$ TOCSY ( $\left.\mathrm{t}_{\mathrm{mix}}=60 \mathrm{~ms}\right)$. Strong H1'-H2' and weak H3'-H4' cross-peaks defined all puckers as C2'-endo. All $X$ dihedral angles were restrained to anti conformations based on lack of strong intraresidue H1'$\mathrm{H} 6 / \mathrm{H} 8$ NOEs. Intermolecular NOEs were identified using $2 \mathrm{D}{ }^{13} \mathrm{C} \mathrm{F}_{2}$ filtered $2 \mathrm{D}$ NOESY $\left(\mathrm{t}_{\text {mix }}=60 \mathrm{~ms}\right)$ and 3D $F_{3}$ filtered, $F_{2}$ edited ${ }^{13} \mathrm{C}$ HMQC-NOESY ( $\mathrm{t}_{\text {mix }}=70 \mathrm{~ms}$ ) in $\mathrm{D}_{2} \mathrm{O}$. Intramolecular NOEs of RNA were identified using $2 \mathrm{D}{ }^{13} \mathrm{C} \mathrm{F}_{1}$ filtered, $\mathrm{F}_{2}$ filtered NOESY $\left(\mathrm{t}_{\text {mix }}=150 \mathrm{~ms}\right)$ in $\mathrm{D}_{2} \mathrm{O}$.

\section{NMR titrations}

NMR titrations were performed by adding unlabeled concentrated RNA $(1-5 \mathrm{mM})$ to ${ }^{15} \mathrm{~N}$-labeled protein (0.1-0.2mM) in NMR buffer (20mM MES pH 6.6, $100 \mathrm{mM} \mathrm{NaCl}$ ) and monitored by ${ }^{1} \mathrm{H}-{ }^{15} \mathrm{~N}-\mathrm{HSQC}$. To monitor the chemical shift perturbations of the tandem RRM mutants upon addition of RNA, 1:1 complexes were directly prepared in NMR buffer (100 mM KHPO $4 / \mathrm{KH}_{2} \mathrm{PO}_{4} \mathrm{pH} 6.6,1 \mathrm{mM}$ DTT) as described under 'NMR sample preparation'.

\section{NMR relaxation and RDC measurements}

Backbone dynamics data of the tandem RRMs in complex with CUUAUUUG were recorded on a 1:1.1 complex of random fractionally deuterated ${ }^{13} \mathrm{C},{ }^{15} \mathrm{~N}$-labeled protein with unlabeled RNA on a Bruker AVANCE $750 \mathrm{MHz}$ spectrometer at $298 \mathrm{~K}$. The heteronuclear ${ }^{1} \mathrm{H}-{ }^{15} \mathrm{~N}$ values were measured with reference and NOE experiments recorded in interleaved fashion, employing water flip-back pulses. Heteronuclear NOE values are reported as the ratio of peak heights in paired spectra collected with and without an initial period (4s) of proton saturation during the 5-s recycle delay. ${ }^{15} \mathrm{~N}$ T1 and T2 values were measured using TROSY-based pseudo-3D experiments employing flip-back pulses and gradient selection (Zhu et al. 2000). T1 spectra were acquired with delays, $T=40,150,300,500,900,1500$, 2200 and $3000 \mathrm{~ms}$, T2 spectra were acquired with CPMG delays, $T=17,34,51,68,103,137,188$, and $239 \mathrm{~ms} .{ }^{15} \mathrm{~N} \mathrm{~T} 1$ and $\mathrm{T} 2$ values were extracted by plotting the decay of $\mathrm{HN}$ volumes and fitting the curves with standard exponential equations using the nlinLS lineshape fitting program within the NMRPipe 
package (Delaglio et al. 1995). Residual dipolar coupling (RDC) restraints were extracted using ${ }^{1} \mathrm{H}-{ }^{15} \mathrm{~N}$ TROSY run on a fully protonated ${ }^{15} \mathrm{~N}$-labeled (1:1.1) tandem RRM-CUUAUUUG complex in NMR buffer (isotropic dataset) and NMR buffer mixed with 4.2\% C12E5 polyethylene glycol / hexanol medium (Rückert and Otting 2000) (anisotropic dataset). RDCs were derived by subtracting the isotropic from anisotropic ${ }^{1} \mathrm{H}$ chemical shift differences between TROSY and anti-TROSY spectra recorded in an interleaved manner. Only un-overlapped peaks were analyzed and RDC restraints were employed only for structured residues with ${ }^{15} \mathrm{~N}$ het-NOE values larger than 0.6 . The RDC rhombicity and anisotropy components were determined in CYANA by grid-search using an initial protein structure and further refined in subsequent structure calculations.

\section{Structure calculation and refinement}

Intramolecular protein distance restraints were derived from $3 \mathrm{D}{ }^{1} \mathrm{H}-{ }^{15} \mathrm{~N}$ NOESY $\left(\mathrm{t}_{\text {mix }}=80 \mathrm{~ms}\right)$ and $3 \mathrm{D}{ }^{1} \mathrm{H}-$ ${ }^{13} \mathrm{C}$ HMQC-NOESY $\left(\mathrm{t}_{\text {mix }}=70 \mathrm{~ms}\right), 3 \mathrm{D}{ }^{1} \mathrm{H}-{ }^{13} \mathrm{C}$ HSQC-aroNOESY $\left(\mathrm{t}_{\text {mix }}=80 \mathrm{~ms}\right)$ and $2 \mathrm{D}$ NOESY $\left(\mathrm{t}_{\text {mix }}=\right.$ $80 \mathrm{~ms}$ ). The protein resonance assignments of the tandem RRM-CUUAUUUG complex and a list of manually assigned protein core NOEs were used as input for automatic peak picking and NOESY assignment using ATNOSCANDID (Herrmann et al. 2002a, 2002b) in a two-step procedure. First intraRRM NOEs were assigned by including only resonance assignments for one individual RRM in two separate runs. Second an ATNOSCANDID NOE assignment was performed using all resonance assignments. In this run a list of upper limit distance restraints combining the restraints obtained in the runs performed with assignments for the individual RRMs was included. This procedure was found to be necessary to obtain the correct global topology for the two RRMs. The resulting peak lists were then checked and supplemented manually with additional picked peaks and several critical manual NOE assignments. The optimized NOESY peak lists from this procedure were re-assigned with the NOEASSIGN module of CYANA 3.96 (Güntert and Buchner 2015) while iteratively adjusting and keeping key manual assignments fixed during iterative refinement of the structure. Intra-protein hydrogen bonds were identified for $\mathrm{HN}$ resonances which were protected during hydrogen-deuterium exchange by reference to intermediate structures and added as restraints in further rounds of structure calculation. Following the determination of the protein structure in the bound state the structure of the complex was determined. Intra-RNA and intermolecular NOESY peaks were picked and assigned 
manually and calibrated using known distances of $\mathrm{H} 5-\mathrm{H} 6$ cross-peaks of pyrimidines. In structure calculations including the RNA, unambiguous intermolecular NOEs were included first for initial positioning of the nucleotides. Intermolecular NOEs with ambiguous assignments were then included as ambiguous restraints in CYANA and assigned unambiguously based on preliminary calculations. To further confirm the intermolecular restraints, we back-calculated short intermolecular distances from our final structures and inspected the spectra for completeness of intermolecular NOEs. Final structure calculations in CYANA included intra-protein, intra-RNA and intermolecular NOEs, protein dihedral backbone restraints, intra protein hydrogen bond restraints, and restraints for sugar pucker and syn or anti conformations identified from NOE patterns of $\mathrm{H} 6$ or $\mathrm{H} 8$ resonances. Protein dihedral backbone restraints derived from TALOS+ (Shen et al. 2009) and additional manually defined $\beta$-hairpin turn restraints were used for the $\mathrm{N}$-terminal $\beta$-hairpin extension. In the final structure calculation 500 structures were calculated with CYANA and the 50 lowest energy structures were selected for refinement with the SANDER module of AMBER12 (Case et al. 2012) using the ff12SB force field with implicit solvent and 20 were selected based on the criteria of lowest amber energy and lowest intermolecular restraint violations.

\section{Isothermal Titration Calorimetry}

ITC experiments were performed on a VP-ITC microcalorimeter (Microcal). Protein was dialyzed in ITC buffer 20mM MES pH 6.6, $100 \mathrm{mM} \mathrm{NaCl}, 1 \mathrm{mM}$ 2-mercaptoethanol. RNA (100-400 $\mu \mathrm{M})$ was dissolved in NMR buffer and titrated into protein (3.5-11 $\mu \mathrm{M})$ in $2 \mu \mathrm{L}$ followed by $8 \mu \mathrm{L}$ (RRM12) or $10 \mu \mathrm{L}$ (RRM1) every $300 \mathrm{~s}$ at $25^{\circ} \mathrm{C}$ with a stirring rate of $307 \mathrm{rpm}$. Raw data was analyzed in Origin 7.0.

\section{Data deposition}

The coordinates for the structural models of DND1-RRM12:CUUAUUUG have been deposited in the Protein Data Bank under ID code PDB xxx, and the assignments have been deposited at BMRB under ID code BMRB: $x x x$. 